Discussion Paper No. 12-054

\title{
An Integrated Assessment Model with Endogenous Growth
}

Michael Hübler, Lavinia Baumstark, Marian Leimbach, Ottmar Edenhofer, and Nico Bauer

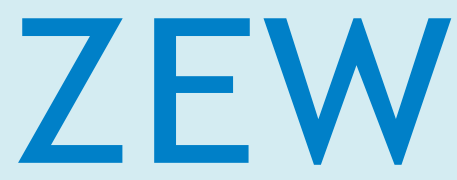

Zentrum für Europäische Wirtschaftsforschung $\mathrm{GmbH}$

Centre for European Economic Research 
Discussion Paper No. 12-054

\title{
An Integrated Assessment Model with Endogenous Growth
}

\author{
Michael Hübler, Lavinia Baumstark, Marian Leimbach, \\ Ottmar Edenhofer, and Nico Bauer
}

Download this ZEW Discussion Paper from our ftp server:

http://ftp.zew.de/pub/zew-docs/dp/dp12054.pdf

Die Discussion Papers dienen einer möglichst schnellen Verbreitung von neueren Forschungsarbeiten des ZEW. Die Beiträge liegen in alleiniger Verantwortung der Autoren und stellen nicht notwendigerweise die Meinung des ZEW dar.

Discussion Papers are intended to make results of ZEW research promptly available to other economists in order to encourage discussion and suggestions for revisions. The authors are solely responsible for the contents which do not necessarily represent the opinion of the ZEW. 


\section{Non-technical Summary}

We introduce endogenous directed technical change into integrated multi-region policy assessment based on macroeconomic theory and evidence. Technical progress can be directed towards labor or energy savings. We distinguish expenditures on innovation and imitation, in other words international technology transfer, and take the role of capital investment in implementing new technologies into account. We study the regional pattern of mitigation costs in form of consumption losses induced by a global carbon budget-based climate policy. Mitigation costs turn out to be robust with respect to a variation in the parameter values within our model of endogenous growth - except the effectivity (in terms of technical progress per unit of investment) of energy specific relative to labor specific innovation and imitation expenditures. This result suggests that an increased effectivity of energy specific innovation and imitation expenditures can overcompensate rising emissions due to economic growth and thus reduce mitigation costs. However, the effectivity is exogenously determined by technological restrictions and at best partly susceptible by economic policy in the short-run. In the medium- to long-run, the effectivity could be improved by emphasizing energy efficiency aspects in education, basic research, infrastructure, structural change and capacity building for R\&D and for the absorption of foreign technologies.

Motivated by recent announcements of providing financial and technological transfers for developing countries, we examine interregional energy saving technology transfer starting at different points of time. Herein, all regions gain from technology transfer due to its growth effect. China appears as the main beneficiary of early technology transfer because of strong international technology spillovers, followed by the region of the developing countries.

Our results suggest that endogenous energy specific technical progress has already been strongly exploited in the business as usual baseline and created baseline consumption gains. This might be due to perfect foresight and regionally weighted global optimization in combination with energy scarcity. But in reality, the baseline gains are not fully exploited on a market base due to risks and frictions and missing information. Realizing these gains probably requires policy support in form of an integrated climate and energy policy concept. Herein, early energy saving technology transfer could be a 'carrot' to encourage developing countries to engage in climate protection. 


\section{Das Wichtigste in Kürze}

In diesem Artikel, führen wir endogenen gerichteten technischen Fortschritt basierend auf makroökonomischer Theorie und Empirie in die integrierte multiregionale Politikanalyse ein. Technischer Fortschritt kann zur Einsparung der Inputfaktoren Arbeit und Energie verwendet werden. Wir unterscheiden zwischen Ausgaben für Innovation und Imitation (internationalen Technologietransfer) und berücksichtigen die Bedeutung von Kapitalinvestitionen für die Implementierung neuer Technologien. Wir untersuchen die regionale Verteilung der Vermeidungskosten, die sich aus einer Klimapolitik mit globalem $\mathrm{CO}_{2}$-Budget ergeben. Die Vermeidungskosten erscheinen weitgehend robust im Hinblick auf die Variation der Parameterwerte im Modell des endogenen Wachstums. Es zeigt sich jedoch, dass eine höhere Effektivität (in Form von technischem Fortschritt pro Investitionseinheit) von energiespezifischer relativ zu arbeitsspezifischer Innovation und Imitation wachstumsbedingt steigende Vermeidungskosten überkompensieren kann. Diese Effektivität ist jedoch exogen durch technische Restriktionen gegeben und bestenfalls teilweise kurzfristig durch Wirtschaftspolitik beeinflussbar. Mittel- bis langfristig könnte die Effektivität durch die Betonung von Energieeffizienzaspekten in Bildung, Grundlagenforschung und Infrastruktur sowie durch die Verbesserung der Kompetenz in Forschung und Entwicklung und in der Absorption ausländischer Technologien verbessert werden.

Motiviert durch die Ankündigungen von finanziellen und technischen Transfers an Entwicklungsländer, untersuchen wir interregionalen energiesparenden Technologietransfer, der zu unterschiedlichen Zeitpunkten beginnt. Dabei profitieren alle Regionen von dem Wachstumseffekt des Technologietransfers. China erscheint als Hauptprofiteur des frühzeitigen Technologietransfers bedingt durch starke internationale TechnologieSpillovers, gefolgt von der Modellregion der Enwicklungsländer.

Unsere Ergebnisse zeigen, dass der energiespezifische technische Fortschritt bereits im Basislauf (BAU) weitgehend ausgeschöpft wird. Dies kann an perfekter Voraussicht und an regional gewichteter globaler Optimierung in Kombination mit Energieknappheit im Basislauf liegen. In der Realität wird dieses Potenzial wegen Risiken, Markthemnissen und mangelnder Information nicht voll ausgeschöpft, so dass ein integriertes Klima- und Energiekonzept sinnvoll erscheint. Dabei kann frühzeitiger Technologietransfer einen Anreiz für Entwicklungsländer bieten, sich an einem Klimaabkommen zu beteiligen. 


\title{
An Integrated Assessment Model with Endogenous Growth
}

\author{
Michael Hübler* Lavinia Baumstark, \\ Marian Leimbach, Ottmar Edenhofer, Nico Bauer
}

August 22, 2012

\begin{abstract}
We introduce endogenous directed technical change into numerical integrated climate and development policy assessment. We distinguish expenditures on innovation $(\mathrm{R} \& \mathrm{D})$ and imitation (international technology spillovers) and consider the role of capital investment in creating and implementing new technologies. Our main contribution is to calibrate and numerically solve the model and to examine the model's sensitivity. As an application, we assess a carbon budget-based climate policy and vary the beginning of energy-saving technology transfer. Accordingly, China is a main beneficiary of early technology transfer. Herein, our results highlight the importance of timely international technology transfer for efficiently meeting global emission targets. Most of the consumption gains from endogenous growth are captured in the baseline. Moreover, mitigation costs turn out to be insensitive to changes in most of the parameters of endogenous growth. A higher effectivity of energy-specific relative to labor-specific expenditures on innovation and imitation reduces mitigation costs, though.
\end{abstract}

JEL Classifications: O11, O30, O44, O47, Q32

Keywords: endogenous growth, directed technical change, technology transfer, integrated assessment, carbon budget, China

${ }^{*}$ Corresponding, leading author, email: huebler@zew.de, tel: +49-621-1235-340, fax: +49-621-12354340, Centre for European Economic Research, Postfach 103443, 68034 Mannheim, Germany. All authors' affiliation: Potsdam Institute for Climate Impact Research, Telegraphenberg A31, 14412 Potsdam, Germany, email: baumstark@pik-potsdam.de, leimbach@pik-potsdam.de, edenhofer@pik-potsdam.de, nicolasb@pik-potsdam.de. We thank Elmar Kriegler for his help regarding IPCC scenarios. We thank the Leibniz Association (WGL) for financial support. 


\section{Introduction}

Innovation as well as imitation and international diffusion of technologies can be a key for successfully coping with poverty and climate change. Herein, (climate) policy interventions have an impact on the strength and direction of innovation, imitation and technology diffusion. Therefore, a (climate) policy analysis that takes these aspects into account requires a rigorous model of endogenous directed technical progress. Setting up such a model and calibrating it to real world data is the first and main contribution of this paper. Due to the uncertainties in the parameter values in a model of endogenous growth, we conduct a careful sensitivity analysis. This is the second contribution of this paper.

It is widely agreed that the OECD countries bear the main responsibility for climate change while the developing countries will bear most of its impacts. Private investment on a national or international scale is expected to bring about the relevant capacities and technologies for climate change mitigation and adaptation. China as a prominent example has successfully improved its energy productivity and has become a leading producer and exporter of clean energy equipment. But in general, many developing and emerging economies lack in financial resources, knowledge, technological capabilities and the ability to adopt foreign technologies. International trade policy and patent regulation (WTO and TRIPS ${ }^{1}$ ) can on the one hand spur innovation but on the other hand hinder international technology diffusion and technological catching up. Therefore, many economies will probably not be able to achieve technical progress, economic development and carbon emissions reductions simultaneously within a short time frame. Thus international support will be required.

Therefore, in recent climate negotiations (Bali Roadmap 2007, Copenhagen 2009 and Cancún 2010 summit), developing countries called for financial and technological support for mitigation, and industrialized countries announced to provide such support. So far, the Kyoto Protocol has enabled international financing in (and technology transfer to) developing countries within the Clean Development Mechanism (CDM) framework. Herein, China has been the biggest seller of CDM credits with a market share of $72 \%$ in 2009 (Kossoy and Ambrosi 2010, section 4). The total volume of CDM transactions amounted to US-\$ 6.5 billion in 2008 and only US-\$ 2.7 billion in 2009 (Kossoy and Ambrosi 2010, section 4). Moreover, developing countries can receive such support through technology funds like the World Bank Climate Investment Funds (World Bank 2010) as announced at the Cancún 2010 summit. In particular, industrialized countries

\footnotetext{
${ }^{1}$ World Trade Organization and Trade-Related Aspects of Intellectual Property Rights.
} 
announced future transfers amounting to US- $\$ 100$ billion per annum by 2020 in the Copenhagen Accord. This volume exceeds the volumes of annual financial transfers within the CDM framework cited above by far. However, no legally binding commitments have been achieved that settle which countries will pay and receive how much beginning at which date. This uncertainty gives rise to the question how mitigation costs of different regions are affected by postponing international technology transfer. Against this background, in this article, we apply our model of endogenous growth to the assessment of mitigation costs induced by a carbon budget-based policy and the costs of delaying international technology transfer. ${ }^{2}$ Thereby, it intends to contribute to the literature that discusses the future of the Kyoto Protocol against the backdrop of efficient (carbon) markets and North-South equity (c.f. Chichilnisky and Heal 2000; Chichilnisky and Sheeran 2009). This is the third contribution of this paper.

Our model approach refers to state-of-the-art theoretical models of endogenous growth. ${ }^{3}$ Product variety models in the style of Romer (1990) describe growth as a process that stems from an increasing number of innovative intermediate products (e.g. Grossman and Helpman 1991). Product quality models in the style of Aghion and Howitt (1992) rather describe growth as a process that stems from quality improvements of products wherein new varieties replace old varieties, which is also called 'creative destruction'. We refer to the latter model type, however on a stylized macro level without treating profit maximizing firms explicitly into account. Acemoglu et al. (2003, 2006) provide microfoundations and a rigorous analysis of the influence of the distance between the technology in practice and the technology frontier (along the lines of the seminal contribution by Nelson and Phelps 1966). They show that an imitation-based strategy is preferable when being further away from the technology frontier while an innovationbased strategy is preferable when being closer to the technology frontier. We follow this idea by including a 'distance to technology frontier' term (more specifically a 'technology pool' term) in our model. Herein, the model allows an endogenous simultaneous choice between innovation and imitation which are treated as substitutes. It basically reproduces the findings by Acemoglu et al. (2003, 2006) endogenously. Furthermore, we follow approaches in the style of Arrow (1962) such as Greiner and Semmler (2002) that view learning related to capital investment as a driver of technical progress. In our context, the positive impact of capital investment on technical progress in an economy is a supplement to the following consideration: New technologies such as energy-saving

\footnotetext{
${ }^{2}$ We leave the specific channels - such as FDI - and policy instruments - for instance a technology fund - for achieving international technology transfer open.

${ }^{3}$ As comprehensively described by Aghion and Howitt (2009), chapter 4 and Acemoglu (2009), chapters 14,15 and 18.
} 
technologies that exist as blueprints become increasingly used in the economy through capital investment. As a result, they become increasingly embodied in the new capital stock and raise its productivity. We implement this feature in the style of the Schumpeterian model as a novel theoretical detail. Finally, we follow the literature in the style of Acemoglu (2002) that emphasizes the possibility to direct technical change towards specific factors depending on the abundance of factors or relative factor prices. Technical progress directed towards a certain factor will reduce the demand for this factor (factor-saving technical progress) when the elasticity of substitution between the production factors is smaller than one, which is the case in our model (in the upper CES level).

However, endogenous growth along these lines of the theoretical literature has not yet been fully worked out in an integrated assessment framework. Therefore, it is our main contribution to implement endogenous, directed technical progress resulting in fully endogenous economic growth into our multi-region integrated assessment model. Therein, our approach contributes to the literature that numerically describes endogenous innovation (e.g. Goulder and Schneider 1999, Popp 2004, 2006, Edenhofer et al. 2005, Kemfert 2005, Otto et al. 2007, 2008, Löschel and Otto, 2009, Gerlagh 2008) and international technology spillovers (e.g. Diao et al. 2005, Leimbach and Baumstark 2010, Hübler 2011). Our model is mostly comparable to the integrated assessment model WITCH (Bosetti et al. 2006). The original version of WITCH, described and applied by Bosetti et al. (2008), focuses on disembodied international technology spillovers of energyspecific R\&D (research and development). Herein, the strength of spillovers depending on the distance to the technology frontier has an inverted U shape. This means, technology spillovers are highest at a medium distance to the technology frontier. Bosetti et al. (2011) apply WITCH to show that innovation policy in combination with climate policy results in substantial efficiency gains. Our model model additionally allows for R\&D and international spillovers that are directed to labor inputs and assumes that spillovers increase in the distance to the technology frontier. The modified version, used by Nicita et al. (2009), also allows for the direction of R\&D towards energy or non-energy (capital and labor) inputs and thus endogenizes crowding out effects. Their model version seems not to model international technology spillovers, though. Their analysis shows that climate policy shifts R\&D more towards energy inputs while R\&D declines in total since total output declines. Our model combines both effects, international spillovers and directed technical change, with respect to labor and energy productivity. Compared to WITCH, our model also represents international (and 'intertemporal') trade in goods which aggravates the numerical solution of the multi-region model. Moreover, 
compared to WITCH, our model represents endogenous resource extraction that yields a kind of Hotelling path. On the contrary, we do not take climate damages into account in our model. We do not model international $R \& D$ spillovers of energy conversion technologies either but apply a global learning curve for the technologies wind and solar photovoltaic. This means, domestic investment costs of these technologies decrease in the installed capacity world-wide. This clearly has an impact on technology choice and technology diffusion. We apply our model to an analysis that is new in the literature: The effects of delaying international technology diffusion.

In our policy analysis, our model of endogenous growth will be embedded into the integrated assessment model REMIND (Refined Model of Investment and Technological Development, Leimbach et al. 2010a, c.f. Figure 3 and Figure 4 in the Appendix), a Ramsey type model of intertemporally optimal investment in physical capital and energy technology capacities. The model version under scrutiny consists of five world regions and includes trade (in a composite commodity, coal, gas, oil, uranium and carbon emissions permits) between these regions. Technology spillovers are controlled in a centralized way. International trade is subject to an intertemporal trade budget restriction following Negishi (1972) which creates a decentralized solution for trade. The macro model is coupled with an energy system module that represents several energy sources and related capacities of energy technologies (coal, gas, oil, uranium, hydro, biomass, solar, wind, geothermal, carbon capture and storage (CCS) of coal, gas and biomass; c.f. Leimbach et al. 2010a, b). The energy system module includes endogenous investment into capacities of different energy technologies as well as learning-by-doing of wind and solar technologies following the literature that emphasizes learning effects (e.g. Crassous et al. 2006, Kahouli-Brahmi 2008). The energy system module takes increasing costs of resource extraction into account as well as operation and maintenance costs. Carbon emissions stemming from fossil fuels burned in production and consumption processes can be translated into resulting temperature increases in a climate module (Tanaka and Kriegler 2007). The climate module is not used in this analysis of endogenous growth, though. The time horizon under scrutiny is 2005 until 2100 in five-year steps.

Section 2 derives our model of endogenous growth from economic theory. Section 3 describes the numerical calibration and shows baseline simulation results. Section 4 applies the model to the assessment of a carbon budget-based climate policy and the delay of energy-saving technology diffusion within the integrated assessment model REMIND (Leimbach et al. 2010a). Section 5 critically discusses the model results and carries out a sensitivity analysis. Section 6 concludes by deriving policy implications. 


\section{Model}

We derive the implementation of directed technical change in an intertemporal optimization framework in four steps from economic theory: (1) We derive the effect of R\&D expenditures on the progress of innovation from a Schumpeterian model of growth. (2) We take investment in physical capital as a driver of innovation into account. (3) We implement interregional technology spillovers. (4) We allow for the direction of technical change towards labor or energy. (Table 6 and Table 7 in the Appendix provide an overview of the sets, variables and parameters of our model of endogenous growth.) In the following, we will describe the first three drivers of technical change separately and finally add them up including the fourth effect. Herein, our model represents the macroeconomic level without modeling firms explicitly. Our treatment of energy-specific technical change refers to productivity gains in using energy in final production. We do not model international R\&D spillovers of energy conversion technologies but apply a global learning curve for new technologies like wind and solar photovoltaic. This means, domestic investment costs of these technologies decrease with the installed capacity world-wide. Table 6 in the Appendix summarizes the model notation.

\section{$2.1 \quad R \& D$ expenditures}

With respect to modeling endogenous growth, we follow the Schumpeterian view of quality improvements as a driver of economic growth-based on the description by Aghion and Howitt (2009), chapter 4. We start with a one-sector production function $Y$ which is increasing in technology $A$. Both are macroeconomic aggregates so that $A=\int_{0}^{1} A_{j} d j$ can be interpreted as an average of individual productivities of firms or sectors $j$ in the economy. In each period a firm spends $R_{j}$ on $R \& D$. Each firm is able to keep part of the generated knowledge as firm-specific knowledge so that it has some monopolistic power and earns a profit. In other words, each firm holds a patent. The same intuition applies to non-profit research institutions in form of earning non-monetary profits such as publications, reputation and political influence, so that we may also interpret non-profit organizations as firms. Now we aggregate individual expenditures to macroeconomic expenditures $R=\int_{0}^{1} R_{j} d j$. On the macro level, $R$ may also include public spending on education, basic research, infrastructure etc., which enhances invention and innovation in the economy. Each innovation process is due to uncertainty regarding its outcome. By the law of large numbers, expenditures will lead to a successful innovation with probability $\mu$ and will not lead to a successful innovation with probability $1-\mu$ on the macro level. Herein, $\mu$ is increasing in $R$ which is endogenously determined. Innovation processes are not only due to uncertainties but also inefficiencies, for example because 
of short time horizons that managers consider for the innovation investment decisions or insufficient protection of intellectual property rights. Such inefficiencies of innovation markets are implicitly captured by the innovation probability $\mu$. Higher inefficiencies reduce the probability of success when spending a certain volume for $R \& D$ resulting in a lower $\mu$. More specifically, following Aghion and Howitt (2009), chapter 4, we write: ${ }^{4}$

$$
\mu=\lambda_{R}\left(\frac{R_{t}}{A_{t}^{R}}\right)^{\sigma_{R}}
$$

$t \in\{2005,2010, . .2100\}$ denotes time, more specifically years increasing in five-year steps. $R_{t}$ denotes aggregated macroeconomic $\mathrm{R} \& \mathrm{D}$ expenditures at time $t$, and $A_{t}^{R}$ stands for the aggregated individual productivities at time $t$ regarding $\mathrm{R} \& \mathrm{D}$ expenditures $R . \lambda_{R}$ determines the impact of $R \& D$ expenditures on the probability of success in a linear fashion. $\sigma_{R}$ creates a decreasing marginal effect of R\&D expenditures on the probability of success with rising expenditures, where $0<\sigma_{R}<1$. Assuming that a new technology is $\gamma>1$ times as productive as the previous technology, the rate of innovation-based technical progress $g_{R}$ can be derived in the following way:

$$
A_{t+5}^{R}=\mu \gamma A_{t}^{R}+(1-\mu) A_{t}^{R} \quad \Leftrightarrow \quad \frac{A_{t+5}^{R}-A_{t}^{R}}{A_{t}^{R}}=\mu(\gamma-1)=: g_{R}
$$

In case of a successful innovation, the new technology $\gamma A_{t}^{R}$ will be applied. In case of no success, the old technology $A_{t}^{R}$ will be used further. ${ }^{5}$ However, the implementation in the REMIND model does not take profit maximization of firms and monopolistic power due to successful innovations explicitly into account. Thus, $A_{t+5}^{R}$ represents an aggregate or average technology level of the economy in period $t$. On this aggregate level, $A_{t+5}^{R}$ can be treated as deterministic representing a certain share $\mu$ of successful innovators in all firms. Our model simulations will treat the technology level as a deterministic variable too.

\subsection{Investment in physical capital}

Additionally, there is an interaction of investment in knowledge creation and investment in capital. On the one hand, the literature based on Arrow (1962) sees knowledge as a by-product of capital accumulation. On the other hand, viewing knowledge as a public good, innovations need time for diffusion through the economy, and they require investment in capital in order to be implemented into production facilities. Therefore,

\footnotetext{
${ }^{4}$ We will add region- and factor-specific indexes in the final set of equations.

${ }^{5}$ One may add depreciation of knowledge which is less common in theoretical growth models than in applied assessment models.
} 
we extend the Schumpeterian point of view in a novel setting in the following general form:

$$
A_{t+5}^{R I}=\left(1+g_{R}\right) A_{t}^{R I}\left(\frac{I_{t}}{K_{t+5}}\right)^{\sigma_{I}}+A_{t}^{R I}\left[1-\left(\frac{I_{t}}{K_{t+5}}\right)^{\sigma_{I}}\right]
$$

$A_{t}^{R I}$ is the productivity correlated with $\mathrm{R} \& \mathrm{D}$ expenditures and investments into physical capital. $I_{t}$ is investment in capital, and $K_{t+5}=(1-\delta) K_{t}+I_{t}$ is the new capital stock, where $\delta$ is the depreciation rate. We assume $\sigma_{I}=1 .^{6}$ Then, according to the equation above, the fraction of the capital stock remaining after depreciation that is renewed by investment uses the newest technology $\left(1+g_{R}\right) A_{t}^{R I}$. The remaining fraction of the capital stock still uses the old technology $A_{t}^{R I}$. As a consequence, the implementation of existing new technologies in production depends on investment, as observed in reality. We can now simplify the equation above and replace $g_{R}$ :

$$
A_{t+5}^{R I}=A_{t}^{R I}\left[1+(\gamma-1) \lambda_{R}\left(\frac{R_{t}}{A_{t}^{R I}}\right)^{\sigma_{R}}\left(\frac{I_{t}}{K_{t+5}}\right)^{\sigma_{I}}\right]
$$

\subsection{International technology spillovers}

In the next step, we will add international technology diffusion following the same line of argumentation and the same specification as before. There are basically two differences to the previous specification. We now assume that expenditures $S$ encompass expenditures on fostering international technology diffusion instead of innovation. They include expenditures of firms on the imitation and adoption of foreign technologies as well as publicly funded projects that enhance the diffusion of technologies. Besides this re-interpretation, a new technology still appears with probability $\mu$ as described by equation (1), but now we assume that each productivity increase, previously occurring at the rate $\gamma-1$, occurs endogenously. This productivity increase depends inversely on the technology level of the recipient economy relative to the world technology pool $\bar{A}$ as suggested by Acemoglu (2009), chapter 18 (c.f. Griffith et al. 2003 reconciling theory and evidence). The rate of technical progress now reads:

$$
g_{S}:=\lambda_{S}\left(\frac{S_{t}}{A_{t}^{S I}}\right)^{\sigma_{S}}\left(\frac{\bar{A}_{t}^{S I}}{A_{t}^{S I}}\right)^{\sigma_{A}}
$$

In general, it is possible that $\lambda_{R} \neq \lambda_{S}$ and that $\sigma_{R} \neq \sigma_{S}$ since innovation and imitation or diffusion are driven by different processes. The term $\left(\frac{\bar{A}_{t}}{A_{t}}\right)^{\sigma_{A}}$ implies that the larger an economy's technology gap relative to the world technology pool the higher is

\footnotetext{
${ }^{6}$ Allowing $0<\sigma_{I}<1$ means, it becomes increasingly difficult or costly to replace a larger fraction of the capital stock by the newest technology.
} 
its growth rate. ${ }^{7}$ As a theoretical result, all economies will grow at the same rate but at different relative distances to the technology pool level depending on their absorptive capacities in the long-run steady state. As suggested by Acemoglu (2009), we compute the world technology pool as the arithmetic average of the technology levels of all regions. As a consequence, all regions contribute to the world technology pool. In some 'technology frontier' specifications often used in the literature, on the contrary, only the technology leader pushes the frontier forward and thus contributes to the global stock of technological knowledge. Herein, we implicitly assume that technological knowledge is heterogenous so that the best available technology does not incorporate all technological know-how, but instead all inventors contribute to a common knowledge pool. Taking again the role of investment into account yields:

$$
A_{t+5}^{S I}=A_{t}^{S I}\left[1+\lambda_{S}\left(\frac{S_{t}}{A_{t}^{S I}}\right)^{\sigma_{S}}\left(\frac{I_{t}}{K_{t+5}}\right)^{\sigma_{I}}\left(\frac{\bar{A}_{t}^{S I}}{A_{t}^{S I}}\right)^{\sigma_{A}}\right]
$$

\subsection{Directed technical change}

Following Acemoglu (2002), we now take directed, i.e. factor-specific technical progress into account. In each region the REMIND production function includes the input factors capital, $K$, labor, $L$, and energy, $E$, and has the following form:

$$
Y_{t}=\left[\alpha_{K}\left(A_{K} K_{t}\right)^{\frac{\sigma_{Y}-1}{\sigma_{Y}}}+\alpha_{L}\left(A_{L t} L_{t}\right)^{\frac{\sigma_{Y}-1}{\sigma_{Y}}}+\alpha_{E}\left(A_{E t} E_{t}\right)^{\frac{\sigma_{Y}-1}{\sigma_{Y}}}\right]^{\frac{\sigma_{Y}}{\sigma_{Y}-1}}
$$

While $A_{K}$ is kept constant, $A_{L t}$ and $A_{E t}$ rise endogenously representing labor- and energy-specific technical progress. Each type of endogenous technical progress is modeled as described above. We choose the elasticity of substitution $0<\sigma_{Y}=0.5<1$ so that the production factors are gross complements. In this case, according to Acemoglu (2002), energy augmenting technical progress, i.e. growth of $A_{E t}$, is labor biased, i.e. it creates excess demand for labor rather than for energy and raises the marginal product of labor more than the marginal product of energy. This means, energy scarcity, e.g. due to climate policy, induces energy saving (energy augmenting) technical progress.

After combining the effects (1) to (4), i.e. adding up Equations (4) and (6), $A_{t+5}=$ $A_{t+5}^{R I}+A_{t+5}^{S I}$, and introducing a factor index $i=\{L, E\}$ and a region index $r$, we obtain

\footnotetext{
${ }^{7}$ According to Acemoglu (2009), chapter 18 one may set $\sigma_{A} \geq 1$ so that economies farther away from the technology pool level have a stronger advantage with respect to technology diffusion.
} 
the final equation below:

$$
A_{r i t+5}=A_{\text {rit }}\left\{1+\lambda_{i} \lambda_{r t}\left[\lambda_{R}\left(\frac{R_{r i t}}{A_{\text {rit }}}\right)^{\sigma_{R}}+\lambda_{S}\left(\frac{S_{r i t}}{A_{\text {rit }}}\right)^{\sigma_{S}}\left(\frac{\bar{A}_{i t}}{A_{\text {rit }}}\right)^{\sigma_{A}}\right]\left(\frac{I_{r t}}{K_{r t+5}}\right)^{\sigma_{I}}\right\}
$$

Since Equations (4) and (6) are combined in an additive way, innovation and imitation are treated as substitutes. As a result and in accordance with the micro-foundations described by Acemoglu et al. (2003, 2006), imitation is more beneficial farther away from the technology frontier (in our case technology pool), while innovation (Equation 4) is more beneficial closer to the technology frontier. Moreover, we extend the parameters $\lambda_{R}$ and $\lambda_{S}$ that determine the strength of innovation and imitation by a factor-specific differential $\lambda_{i}$ and an interregional differential $\lambda_{r t}$. Herein, $\lambda_{i}$ might differ between energy and labor due to technological reasons, i.e. the value of energy saved by a certain volume of $R \& D$ investment can differ from the value of labor saved by the same volume of R\&D investment. ${ }^{8} \lambda_{r t}$ is - besides other aspects - determined by the educational level (human capital) of the respective region. The important role of education for innovation and imitation (absorptive capacity) has often been emphasized in the theoretical and empirical literature (Nelson and Phelps 1966, Benhabib and Spiegel 2005, Kneller 2005). Herein, regional education levels may change over time and in particular converge to equal levels across regions in the distant future.

The overall objective of our Ramsey type optimization model is the weighted sum of utility drawn from per capita consumption across all regions, cumulated and discounted over the time horizon. Regional weighting follows Negishi (1972). Expenditures related to knowledge creation, which we call $R_{\text {rit }}$ and $S_{\text {rit }}$ create costs in form of foregone consumption $C_{r t}$ like usual investment in capital $I_{r t}$. In other words, final output can directly be used as an intermediate input for the creation of knowledge so that consumption in each region is given by:

$$
C_{r t}=Y_{r t}+M_{r t}-I_{r t}-Q_{r t}-R_{r L t}-R_{r E t}-S_{r L t}-S_{r E t}
$$

The marginal product of physical capital $K_{r t}$ rises as a consequence of technical progress which stimulates capital investment $I_{r t}$. Additionally, the REMIND model encompasses an energy system module that distinguishes several energy sources (coal, gas, oil, uranium, hydro, biomass, solar, wind, geothermal). Investments into capacities of the related energy technologies, fuel, operation and maintenance costs are also subtracted from the budget like investment in physical capital as a production factor.

\footnotetext{
${ }^{8}$ For example, a state-of-the-art washing machine will save energy and save time spent for operating it to different extents.
} 
They are subsumed under energy system expenditures $Q_{r t}$ in the equation above. Finally, $M_{r t}$ denotes net imports of each region. The REMIND model applies an algorithm based on Negishi (1972) that adjusts regional weights in the welfare function such that the intertemporal trade budget is equal to zero for all regions in 2150. This algorithm creates a decentralized Nash solution with respect to interregional trade. $M_{r t}$ represents trade in goods and services as well as international transfers. The latter will be important in our analysis of financing international technology diffusion. Obviously, any interregional transfer $M_{r t}$ can be used for consumption and the various kinds of investment in physical capital, energy technology capacities, innovation and imitation such that the resulting investment pattern is optimal.

\subsection{Energy system}

The energy system ${ }^{9}$ is mainly characterized by a rich technology portfolio and diversity of primary energy sources, namely coal, oil, natural gas, uranium, biomass, solar, wind, hydro and geothermal. (Their developments over time are shown in Figure 5e in the Appendix.) Secondary energy carriers are electricity, heat, hydrogen, other liquids, solid fuels, gases, transport fuel petrol and transport fuel diesel. Therein, the model assumes a linear substitution possibility between competing technologies for secondary energy production. From the energy use side, total energy used in production and consumption consists of stationary energy and transport energy (see Figure 4 in the Appendix). Stationary energy is further split into electricity and non-electricity energy. Transport energy is further split into liquid fuels and hydrogen.

System integration costs and resource availability (resource quality) lead to marginal costs of energy generation that rise in the annual technology deployment and in resource extraction respectively. They therefore dampen the expansion of the energy technologies represented in the model. Therein, the availability of (exhaustible) fossil resources is modeled via supply functions that include cumulative extraction costs and take regional resource endowments into account.

Endogenous technological learning, on the contrary, lowers marginal costs of wind and solar technologies depending on their cumulative technology deployment (cumulated energy generation) following Barreto (2001). It creates a kind of positive feedback and therefore helps expand wind and solar capacities over time. This can partly explain the expansion of wind and in particular solar power in the model (see Figure 5e in the

\footnotetext{
${ }^{9}$ For further details see http://www.pik-potsdam.de/research/sustainable-solutions/models/ remind/remind-code.
} 
Appendix). Nonetheless, biomass expands even more over time although it does not include a learning mechanism. Non-renewable energies are not due to learning effects. A larger endowment with a fossil resource, say gas, results in lower marginal extraction and energy generation costs and thus in the expansion of investments into its capacity. As a consequence of carbon pricing, fossil energies are clearly reduced over time under climate policy (see Figure 5e). Allowing for learning effects, say in gas power, could enhance fossil fuel use under climate policy to some extent. Therein, we do not allow for endogenous R\&D in any energy technologies. R\&D in energy technologies could help expand non-fossil technologies and improve fossil technologies.

The macroeconomic module and the energy system module are integrated using a hard-link that ensures simultaneous equilibria on all energy and capital markets (c.f. Bauer et al. 2006). From the macroeconomic perspective, this means that the investments in energy conversion technologies and the demand for final energy carriers required for the generation of economic income are in balance. From the energy system perspective, the supply of primary energy carriers, the investments into energy conversion technologies and thus the supply of final energy carriers are also in balance.

In equilibrium, the energy sector allocates the scarce resources of capital and primary energy to energy technologies in accordance with the prices for these factors, the price for carbon emissions and the prices for final energy carriers that are supplied to the macro module. The conversion technologies require investments into their capacity stocks. These capacities limit the specific flows of energy converted from one form into another form. For example, built gas power plant capacities limit the conversion of gas into electricity. The technology richness and the diversity of energy technologies imply that the equilibrium solution for technology choice regarding scale, timing and location of each technology depends on the prices for capital and energy. Cumulative consumption of exhaustible energy carriers and carbon emissions as well as changing demand structures for final energy imply sequences of technology transitions. For example, the transition from coal power to wind and finally solar power will be accelerated if the carbon price increases and exceeds a certain threshold so that the technologies become profitable. Investments in energy technologies are financed via the savings of the representative consumer who in turn receives the return on investment.

\section{Calibration}

We aggregate the integrated assessment model REMIND to five world regions: INA consists of Africa, Latin America, India and other Asia, i.e. it includes major low-income countries. China is denoted by CHN. ROW consists of Middle East, Japan, Russia and 
the rest of the world, i.e. it is on average a middle-income region. EUR consists of the European Union EU 27. USA denotes the United States of America. The overall calibration follows the version REMIND-R 'RECIPE' (Edenhofer et al. 2009). With respect to the population scenario, we refer to the UN (2008) projections. The respective medium scenario peaks at around 9 billion people at the end of the century. Within our model of endogenous growth, we need to calibrate the parameters $\lambda_{i}$ (factor specialty of technical progress), $\lambda_{r 2005}$ (education level in 2005), $\lambda_{R}$ (coefficient of innovation expenditures), $\lambda_{S}$ (coefficient of imitation expenditures), $\sigma_{R}$ (exponent of innovation expenditures), $\sigma_{S}$ (exponent of imitation expenditures), $\sigma_{A}$ (exponent of the technology gap term) and $\sigma_{I}$ (exponent of the investment term). Table 7 in the Appendix summarizes the parameters and the corresponding values that will be derived in the following. Our calibration strategy is based on (1) econometrically estimated values, (2) historical statistical reference values and (3) future reference values derived from existing scenario simulations:

\subsection{Econometric estimations}

Griffith et al. (2003) reconcile the theoretical literature on Schumpeterian endogenous growth with the econometric literature on $\mathrm{R} \& \mathrm{D}$, growth and convergence. They review the empirical findings on the influence of R\&D expenditures per GDP on productivity growth as a macroeconomic social benefit and list some examples: Griliches and Lichtenberg (1984) find values of 0.21-0.76, Schankerman (1981) finds 0.24-0.73, and Scherer $(1982,1984)$ obtains $0.29-0.43$. In general, this literature strand finds a positive and statistically significant influence of $R \& D$ expenditures on productivity growth. These values translate into the $\mathrm{R} \& \mathrm{D}$ coefficient $\lambda_{R}$ in our model. However, the findings differ across studies depending upon the underlying data sample, the definition of $\mathrm{R} \& \mathrm{D}$ (private, public or both) and the inclusion or exclusion of international R\&D spillovers (Griffith et al. 2003). Griffith et al. (2004) find values around 0.4 depending upon the model specification (including R\&D expenditures per GDP as a lagged variable). Zachariadis (2003) also finds values around 0.4. In accordance with this literature strand, we set $\lambda_{R}$ $=0.4$. Note that different to the econometric literature we include R\&D expenditures divided by the current technology level as in the theoretical literature (instead of R\&D expenditures divided by GDP) and additionally the share of capital investment in GDP.

Griffith et al. (2004) additionally include R\&D expenditures per GDP multiplied by the technology gap which corresponds to the term $\left(\frac{S_{t}}{A_{t}}\right)^{\sigma_{S}}\left(\frac{\bar{A}_{t}}{A_{t}}\right)^{\sigma_{A}}$ in our model. They find coefficients of $0.6-1.2$. These coefficients translate into the R\&D coefficient $\lambda_{S}$ for technology diffusion and imitation. Herein, different to our specification, Griffith et al. (2004) include the technology gap term in logarithmic form, and they use the 
technology frontier, i.e. the best available technology, instead of the average technology level. Since our specification deviates from this econometric specification, we set $\lambda_{S}$ to a lower number of 0.12 , which yields realistic productivity growth rates as described below.

Furthermore, Zachariadis (2003) regresses the logarithmic rate of patenting in an industry on the logarithmic R\&D intensity based on a Schumpeterian model of growth. This helps us set the exponent of R\&D expenditures denoted by $\sigma_{R}$. Zachariadis (2003) finds values around 0.2 for own-industry R\&D (and about 0.6 for aggregate $\mathrm{R} \& \mathrm{D}$ ). We set $\sigma_{R}=0.1$ in order to better match the historical $\mathrm{R} \& \mathrm{D}$ expenditures as described below.

\subsection{Historical data}

The theoretical and econometric literature views education (human capital) as an important determinant of productivity growth through $\mathrm{R} \& \mathrm{D}$ and technology diffusion (c.f. Nelson and Phelps 1966, Crespo et al. 2004, Benhabib and Spiegel 2005, Kneller 2005). Herein, the absorptive capacity for the adoption of newly arriving technologies is supposed to increase not only in education and skills but also in the existing infrastructure, especially with respect to access to sources of knowledge and information technologies. Also, the existing technologies in practice are supposed to ease the adoption of new technologies. We follow this view by setting the coefficient $\lambda_{r 2005}$ that affects both, innovation and diffusion of technologies, depending on region-specific levels of education and infrastructure as a determinant of the absorptive capacity. We choose the parameters based on education and infrastructure indicators as reported by WDI (2010). ${ }^{10}$ Moreover, we assume that regions that lack in education and infrastructure catch up over time so that $\lambda_{r t}$ converges. Herein, we assume that all regions will reach the maximal value of one in 2100 (as illustrated in Figure 5 in the Appendix).

Table 1 confronts the results of our simulations for business as usual without climate policy, BAU, with the reference data, REF, obtained from WDI (2010) and IEA (2010). Herein, we compute averages over the time span 1996-2006 (in order to avoid the use of outlier values). Obviously, the model results match the reference data well in many cases, but there are also significant deviations, e.g. the growth rates of energy productivity in

\footnotetext{
${ }^{10}$ We examine primary, secondary and tertiary education enrolment and completion ratios as well as infrastructure indicators such as internet and telephone access ratios. We set the highest value to one and measure the other values relative to one. Then we compute the average of the rankings according to the different indexes. The data in general yield the ranking USA, EUR, ROW, CHN, INA. We follow this ranking. However, it is difficult to make a decisive choice on the indicators to be included. Therefore, we adjust the education indicators such that the resulting GDP growth rates better match the historical data. This adjustment may also consider region size effects such that the regional aggregation chosen does not arbitrarily influence the regional innovative performances.
} 


\begin{tabular}{lllrrrrr}
\hline Symbol & Explanation & Scen. & INA & CHN & ROW & EUR & USA \\
\hline \hline \multirow{2}{*}{$g\left(Y_{r 2005}\right)$} & \multirow{2}{*}{ GDP growth } & BAU: & 4.7 & 10.1 & 3.5 & 2.8 & 3.5 \\
& & REF: & 4.0 & 9.2 & 2.4 & 2.5 & 3.0 \\
$g\left(Y_{r 2005} / L_{r 2005}\right)$ & Labor prod. growth & BAU: & 3.0 & 9.5 & 2.5 & 2.6 & 2.5 \\
& & REF: & 2.2 & 8.4 & 1.3 & 2.2 & 2.0 \\
$g\left(Y_{r 2010} / E_{r 2010}\right)$ & Energy prod. growth & BAU: & 0.9 & 2.6 & 0.9 & 0.8 & 1.3 \\
& & REF: & 0.8 & 3.6 & 0.6 & 2.2 & 2.1 \\
$I_{r 2005} / Y_{r 2005}$ & Investment to GDP & BAU: & 20 & 37 & 28 & 29 & 28 \\
& & REF: & 22 & 37 & 23 & 20 & 19 \\
$R_{r L 2005} / Y_{r 2005}$ & Labor inno. expd. & BAU: & 0.5 & 1.7 & 0.8 & 1.8 & 3.3 \\
& & REF: & 0.7 & 0.9 & 2.2 & 1.8 & 2.6 \\
$R_{r E 2005} / Y_{r 2005}$ & Energy inno. expd. & BAU: & 0.2 & 0.6 & 0.1 & 0.2 & 0.2 \\
& & REF: & na & na & na & 0.4 & 0.5 \\
$S_{r L 2005} / Y_{r 2005}$ & Labor imit. expd. & BAU: & 1.2 & 3.6 & 0.3 & 0.2 & 0.3 \\
$S_{r E 2005} / Y_{r 2005}$ & Energy imit. expd. & BAU: & .06 & .30 & .04 & .03 & .05 \\
& & & & & & & \\
\hline
\end{tabular}

Table 1: Comparison of regional model results for 2005 under BAU with reference values REF computed as averages from 1996 to 2006 taken from WDI (2010) and for energyspecific R\&D from IEA (2010). $g$ denotes an average yearly growth rate over a five-year period. All values are reported in percent. (We report model results for 2010 in case of $g\left(Y_{r 2010} / E_{r 2010}\right)$ since the model yields negative energy productivity growth for some regions in 2005 due to initial adjustment effects.)

Europe and in the USA. Furthermore, Figure 5 and Figure 6 in the Appendix illustrate relevant indicators of the model dynamics. Herein, it is important to note that our optimization model generates the globally, socially optimal allocation of expenditures on imitation and innovation. This means, the positive external effect of international technology spillovers is internalized. International trade, on the contrary, occurs in a decentralized Nash game.

Basically, the high-income regions USA and EUR follow innovation-based strategies while the low-income regions INA and CHN follow imitation-based strategies as suggested by Acemoglu et al. $(2003,2006)$. The reason for this outcome is the advantage of the high-income countries in terms of education, existing technologies and capital on the one hand and the advantage of the low-income countries in terms of the potential to absorb technologies from abroad due to the low quality of their own technologies on the other hand.

According to Figure 5b, economic growth is in particular substantial in INA. Therein, 
population growth is a main driver. INA has initially the largest share in global population which even increases over time (see Figure 5a). Furthermore, Figure 5c shows our stylized assumption that INA's education level catches up to that of the other countries until 2100. This assumption enhances innovation and imitation via $\lambda_{r t}$ in Equation (8). Nonetheless, Figure $6 \mathrm{a}$ and $\mathrm{b}$ show that the productivity growth rates are moderate so that INA's productivity stays well below those of the technological leaders USA and EUR. Herein, labor productivity is equivalent to per capita income which stays low in INA. Accordingly, population growth is the major driver of the strong long-run GDP growth.

According to Figure 6c, the USA are clearly the technological leader regarding laborspecific R\&D (innovation) expenditures per GDP, followed by Europe in most periods (and China in the initial phase of strong economic growth). On the contrary, imitation plays a minor role in the USA and Europe regarding imitation expenditures per GDP (Figure 6e/f), while it plays a major role in China and INA. Nonetheless, China also spends the most on energy-specific innovation per GDP, followed by INA in most periods. The probable reason is that the energy productivity in these regions is initially very low so that innovation as well as imitation create a strong benefit per unit invested. The USA and Europe have initially a rather high energy productivity so that investments in energy productivity are less beneficial. It is also obvious (Figure 6d/f) that all regions spend less on both, energy-specific innovation and imitation, as a fraction of GDP over time, while energy productivity steadily rises over time (Figure $6 \mathrm{~b}$ ).

While data about population, GDP and energy inputs are available across almost all countries and years under scrutiny, there are limited data on $R \& D$ expenditures in developing countries. Nevertheless, it is well-known that mainly the industrialized regions drive innovation which is reflected in their $R \& D$ expenditures. ${ }^{11}$ Moreover, data sources report total $R \& D$ expenditures but not labor-specific $R \& D$ expenditures as required for our model. Nevertheless, economic growth is mainly driven by labor-specific technical progress in our model as in many growth models so that it is a direct substitute for general technical progress. Energy-specific R\&D expenditures are available from IEA (2010). However, the data cover less than the OECD countries. Finally, there are probably no data available about expenditures on the adoption and imitation of products and processes (on a country level). Therefore, we suppose that these expenditures have a similar magnitude as R\&D expenditures. Therein, in our model R\&D expenditures mainly depend on the exponents $\sigma_{R}$ and $\sigma_{S}$, i.e. a higher exponent creates ceteris paribus

\footnotetext{
${ }^{11}$ SEI (2006) reports the global shares in total R\&D expenditures of 729 bill. US- $\$$ in the year 2000 as follows: North America 39.1, Asia 28.7, Europe 27.9, South America and Caribbean 2.5, Oceania 1.2, Africa 0.6.
} 
higher R\&D and imitation expenditures. Hence, we reduce $\sigma_{S}$ to 0.01 (compared with $\left.\sigma_{R}=0.1\right)$ so that expenditures on innovation $(\mathrm{R} \& \mathrm{D})$ and for imitation (adoption) of technologies per GDP generated by the model have a similar magnitude.

Finally, the strength of technical progress across the factors labor and energy is adjusted so that it better matches the historical data in terms of labor and energy productivity growth. Herein, we set $\lambda_{L}=1$ and $\lambda_{E}=3$.

\subsection{Future scenarios}

Table 2 compares our model results with scenarios B1 (B1T1 ASF) and B2 (B2BC Minicam) by IPCC (2000) which come closest to our scenario among the IPCC scenarios.

\begin{tabular}{lllr}
\hline Symbol & Explanation & Scen. & Result \\
\hline \hline \multirow{2}{*}{$L_{2100}$} & Global population (= labor force) [bill.] & BAU: & 9.1 \\
& & B1: & 7.1 \\
& & B2: & 10.4 \\
$Y_{2100}$ & Global GDP [trill. US- $\$$ ] & BAU: & 300 \\
& & B1: & 471 \\
$E_{2100}$ & Global primary energy cons. p.a. [EJ] & BAU: & 354 \\
& & B1: & 790 \\
& & B2: & 1370 \\
$Q_{2005-2100}$ Global cumulated carbon emissions [Gt] & BAU: & 1258 \\
& & B1: & 1345 \\
& & B2: & 1290 \\
& & & \\
\hline
\end{tabular}

Table 2: Comparison of global model results for 2100 under BAU with reference values of scenarios B1 (B1T1 ASF) and B2 (B2BC Minicam) by IPCC (2000).

Scenario B1 assumes low population growth and relatively high economic growth, a low primary energy intensity, a low carbon intensity and a high fossil fuel availability in combination with global economic and climate policy solutions. Scenario B2 assumes medium population growth and medium to low economic growth, a medium to high primary energy intensity, a balanced carbon intensity and a low fossil fuel availability in combination with regional economic and climate policy solutions.

In this sense, we follow medium to optimistic assumptions on future socio-economic developments. The regional time paths of important socio-economic indicators created by our model are illustrated in Figure 5 in the Appendix. Therein, the primary energy mix is characterized by the dominance of fossil fuels in (particular coal) for most decades 
of the century (see Figure 5e in the Appendix). Coal is a cheap and abundant energy source, and impacts of carbon emissions are not internalized in a business as usual (BAU) scenario. However, wind and later on even more solar power are significantly expanded due to learning-by-doing effects. Moreover, biomass is strongly used, mostly in order to meet the increasing demand on transportation fuels. The resulting baseline emissions are comparatively low.

\section{Assessment}

This section applies our model exemplarily to the assessment of (1) a carbon budgetbased climate policy and (2) an analysis od delayed energy-saving technology transfer.

\subsection{Carbon budget-based climate policy}

We first impose a budget of global emissions cumulated from 2005 to 2100 amounting to 400Gt of carbon (following Meinshausen et al. 2009 and Allen et al. 2009). The emissions budget is supposed to translate into a temperature goal of about two degree in a statistically robust way. Emissions permits are allocated across regions following a Contraction and Convergence approach (GCI 1990). Therein, per capita emissions in 2005 follow actually measured per capita emissions in 2000. Per capita emissions then converge to equal levels across regions until 2050 such that the budget constraint is fulfilled. We call this climate policy scenario POL.

Herein, the model generates the globally, socially optimal allocation of expenditures on imitation and innovation. This means, the positive external effect of international technology spillovers is internalized. Moreover, this globally, socially optimal solution is independent of distribution matters such as the permit allocation scheme. The permit allocation scheme of course affects regional consumption losses stemming from climate policy. Finally, the REMIND model applies the Negishi (1972) algorithm such that regions are not allowed to create debts or surpluses beyond 2100. Therefore, international transfers can be interpreted as loans that are granted in earlier periods and payed back in later periods.

Table 3 and Table 4 show the difference between POL as described above and BAU as discussed in the previous section for relevant indicators. While Table 3 shows the results for the initial periods, Table 4 shows the results as averages over the time horizon 2005 until 2100. In Table 3, the policy effects have an order of magnitude of around 0.001 to more than one percentage points in terms of growth rates or shares in GDP. In Table 4, the policy effects have an order of magnitude of around 0.001 to more than 


\begin{tabular}{llrrrrr}
\hline Symbol & Explanation & INA & CHN & ROW & EUR & USA \\
\hline \hline & & & & & & \\
$\Delta g\left(Y_{r 2005}\right)$ & GDP growth & -.02 & -.05 & -.09 & -.12 & -.13 \\
$\Delta g\left(Y_{r 2005} / L_{r 2005}\right)$ & Labor prod. growth & -.02 & -.05 & -.09 & -.12 & -.13 \\
$\Delta g\left(Y_{r 2005} / E_{r 2005}\right)$ & Energy prod. growth & 1.28 & 1.23 & 1.12 & 1.04 & .69 \\
$\Delta\left(I_{r 2005} / Y_{r 2005}\right)$ & Investment to GDP & .17 & .08 & .01 & -.08 & -.16 \\
$\Delta\left(R_{r L 2010} / Y_{r 2010}\right)$ & Labor inno. expd. & -.02 & -.03 & -.01 & -.01 & -.03 \\
$\Delta\left(R_{r E 2005} / Y_{r 2005}\right)$ & Energy inno. expd. & .02 & .02 & .01 & .01 & .05 \\
$\Delta\left(S_{r L 2010} / Y_{r 2010}\right)$ & Labor imit. expd. & -.002 & -.002 & -.003 & -.012 & -.031 \\
$\Delta\left(S_{r E 2005} / Y_{r 2005}\right)$ & Energy imit. expd. & .002 & .004 & .003 & .005 & .029 \\
& & & & & & \\
\hline
\end{tabular}

Table 3: Impacts of policy POL (carbon budget) with respect to BAU; changes in yearly growth rates and ratios p.a. in the initial years 2005 or 2010 in percentage points. (E.g. a change from $1.100 \%$ p.a. to $1.099 \%$ p.a. is a -0.001 change in the table. We report model results for 2010 in several cases when the values in 2005 deviate from the general model behavior due to initial adjustment effects.)

0.01 percentage points in terms of growth rates or shares in GDP. Significant changes can be observed for energy productivity growth which is partly due to shifts in R\&D investments. Obviously, the effects are stronger in earlier periods than in later periods in accordance with the general behavior of growth models, in which the system initially changes strongly until a steady state is reached. In both tables, the effects have the expected signs: Investments in energy-saving innovation and imitation increase due to the emissions restriction while investments in labor-saving innovation and imitation decrease. ${ }^{12}$ As a consequence, GDP growth rates also decrease. Notably, the investment share in GDP increases in some regions and years (and also on average as shown in Table 4), probably since a higher investment share enhances the implementation of energysaving technologies in physical capital as incorporated in our model of technical progress.

We also examine how the directed technical change implemented in our macroeconomic module affects the development of energy conversion technologies in our energy module. It turns out that technical change directed towards labor productivity leads to a much stronger and earlier decarbonization of energy supply: In particular the capacities of CCS, furthermore of renewables, expand earlier and more strongly. But labor productivity growth also results in a higher demand for fossil fuels, in particular in de-

\footnotetext{
${ }^{12}$ Nevertheless, there can be single cases with opposite signs in general.
} 


\begin{tabular}{llrrrrr}
\hline Symbol & Explanation & INA & CHN & ROW & EUR & USA \\
\hline \hline$\Delta \varnothing g\left(Y_{r}\right)$ & GDP growth & -.003 & -.004 & -.001 & -.002 & -.002 \\
$\Delta \varnothing g\left(Y_{r} / L_{r}\right)$ & Labor prod. growth & -.003 & -.004 & -.001 & -.002 & -.002 \\
$\Delta \varnothing g\left(Y_{r} / E_{r}\right)$ & Energy prod. growth & .052 & .054 & -.001 & .042 & .036 \\
$\Delta \varnothing\left(I_{r} / Y_{r}\right)$ & Investment to GDP & .002 & .017 & .006 & .001 & .003 \\
$\Delta \varnothing\left(R_{r L} / Y_{r}\right)$ & Labor inno. expd. & -.006 & -.008 & -.004 & -.008 & -.012 \\
$\Delta \varnothing\left(R_{r E} / Y_{r}\right)$ & Energy inno. expd. & .010 & .019 & .005 & .007 & .009 \\
$\Delta \varnothing\left(S_{r L} / Y_{r}\right)$ & Labor imit. expd. & -.005 & -.006 & -.001 & -.001 & -.001 \\
$\Delta \varnothing\left(S_{r E} / Y_{r}\right)$ & Energy imit. expd. & .004 & .007 & .002 & .001 & .002 \\
& & & & & &
\end{tabular}

Table 4: Impacts of policy POL (carbon budget) with respect to BAU; changes in yearly growth rates and ratios p.a. are expressed as averages over the time horizon 2005 to 2100 in percentage points. (E.g. a change from $1.100 \%$ p.a. to $1.099 \%$ p.a. is a -0.001 change in the table.)

veloping regions (CHN, INA). Technical change directed towards energy productivity has basically opposite effects: A lower demand for fossil fuels is detrimental for resource owners (subsumed in ROW). Investments in energy generation capacities (especially CCS and renewables) are lower (especially under POL) than without energy-specific technical progress. Overall, all regions benefit from labor- as well as energy- specific technical progress.

Figure 7 in the Appendix summarizes the most important indicators of BAU shown in Figures 5 and 6 for the POL scenario. Figure 7a indicates that POL GDP does not visibly change compared to BAU GDP in Figure 5a. Figure 7b depicts that energy productivity does significantly rise in POL in all regions. This means, climate policy results in a reduction of energy intensity via substitution effects and probably to a smaller extent via technical progress. Figure 7c however shows that the decarbonization of energy supply is a much stronger effect than the improvement in the energy productivity: Emissions decrease in all regions to a larger extent than energy productivity increases. Figures $7 \mathrm{~d}$ and $7 \mathrm{f}$ show that energy-specific innovation and imitation expenditures slightly increase under POL. (Note the extended scale of the y-axis in these figures compared to $6 \mathrm{~d}$ and 6f.) Figure 7e finally reveals how the decarbonization is achieved: Biomass, solar and geothermal expand strongly over time. Wind and hydro, and nuclear (uranium) too, expand earlier and to a somewhat larger extent. Despite the use of CCS, coal power 
is tremendously reduced over time. Gas which can serve as a substitute for coal with lower carbon content is only to a small extent reduced. Oil is reduced to a relatively small extent too.

Moreover, it has been shown in related previous studies that the introduction of climate policy results in a re-evaluation of fossil resources. Based on REMIND simulations, this is analyzed in Lüken et al. (2011). Changes in the trade of fossil resources are discussed in Leimbach et al. (2010b). Herein, Lüken et al. (2011) find that the devaluation of tradable fossil energy endowments contributes to a large extent to the climate policy costs of fossil fuel exporting regions. Moreover, they find that given a certain emissions target, a reduced availability of low-carbon technologies increases the volume of emissions permits trade and the magnitude of redistribution effects.

For comparison, we run the following experiment, denoted by 'Fixed': ${ }^{13}$ We run BAU. Then we fix the expenditures on innovation and imitation $\left(R_{\text {rit }}, S_{\text {rit }}\right)$ at their BAU levels and run POL. We compute differences between POL and BAU and compare the results with the differences between POL and BAU computed previously, denoted by 'Endogenous'. It turns out that all regions benefit from policy induced technical progress in experiment 'Endogenous' compared to 'Fixed'. However, the difference in mitigation costs between 'Fixed' and 'Endogenous' has a similarly small magnitude as in the results presented in Table 3 and Table 4, i.e. about 0.01 percentage points.

Finally, in an additional experiment, we take the investment over capital $\left(\frac{I}{K}\right)$ ratio for each year from a benchmark run and fix it. Hence, it appears as a time variant parameter in the equation that governs technical progress. (In the usual run, $\frac{I}{K}$ is endogenous.) Then we run a climate policy scenario. Based on the numerical results and on theoretical intuition, we identify the following effects:

Since capital investment $I$ does not only contribute to the capital stock $K$ but also to the knowledge (technology) stock $A$, each marginal unit of $I$ creates an additional marginal beyond the pure expansion of the capital stock. This applies in particular to earlier periods, because rising $A$ (which does not depreciate like $K$ ) creates a benefit in all future periods. Thus, comparing our model where capital investment enhances technical progress to a usual Ramsey model with endogenous capital investment, we find: $I$ will on average increase, and it will be shifted from future to present periods. Climate policy can enhance this effect, in particular with respect to energy productivity. Additionally, climate policy leads to higher investments in capacities of low-carbon technologies. These investments rival the investment in energy-specific technical progress. This effect counteracts the effect described above. However, the effects are relatively

\footnotetext{
${ }^{13}$ Not explicitly shown in the tables.
} 
small in numerical terms. Independent of such policy-induced effects, the inclusion of physical capital in the function that describes technical progress significantly influences the baseline (BAU) path of technical progress. Herein, Figure 5d shows that all countries except INA have initially higher investment ratios $\left(\frac{I}{Y}\right.$ and thus $\left.\frac{I}{K}\right)$ than in the long-run steady state. The rise in $\frac{I}{K}$ creates an additional growth enhancing effect in early periods and enhances the 'steady state convergence' behavior of the model.

\subsection{Delayed energy-saving technology transfer}

In the following, we will assess in how far postponing energy-specific international technology transfer affects mitigation costs given the previous climate policy. International technology transfer requires a sufficient absorptive capacity determined among other factors by the business and legal environment. It requires investments in the absorption and imitation of technologies and in physical capital financed from national or international sources. Herein, climate policy can play an active role in creating the necessary absorptive capacity and fostering national and international financing.

Accordingly, in our model, we interpret the spillover term $\left(\frac{\bar{A}_{t}}{A_{t}}\right)^{\sigma_{A}}$ as the channel of international technology transfer under scrutiny. Energy-specific imitation expenditures $S_{r E t}$ enable the use of this channel and can be financed within each country as well as through international transfers (in form of the composite commodity) within the general budget (Equation 9). Postponing international technology transfer is represented in the following stylized way: Energy-specific imitation expenditures $S_{r E t}$ are exogenously bound to a value close to zero for all regions and all periods before each year $t_{0} \in\{2010,2015,2020,2025,2030,2035,2040\}$. This means, we run one additional $\mathrm{BAU}$ and POL scenario for each of the seven delay periods. From $t_{0}$ on, energy-specific interregional technology diffusion evolves endogenously as before. Herein, the relaxation of imitation expenditures at $t_{0}$ is anticipated.

Figure 1 plots the regionally different effects of postponing energy-specific technology diffusion in form of the difference between consumption in a baseline scenario BAU where financing is postponed versus consumption in the baseline scenario BAU where financing starts immediately in 2005 relative to consumption in the latter scenario. In all calculations of consumption losses, we cumulate consumption losses between 2005 and 2100 and discount at a rate of $3 \%$ per year.

Obviously, postponing creates consumption losses that range from less than 0.1 to more than 0.5 percentage points for all regions due to a higher energy demand per output since energy-specific technical progress is hindered. Accordingly, early investment in energy-saving technology diffusion is beneficial for all regions, given our model setup. 


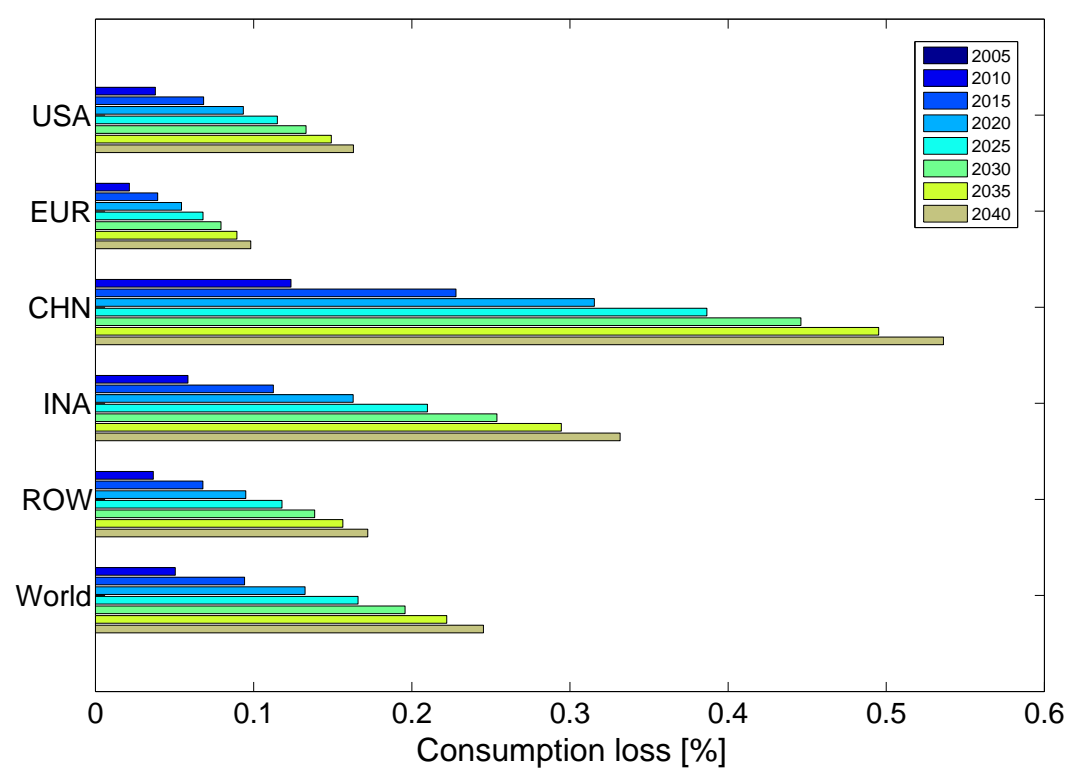

Figure 1: Regional effects of postponing international transfers of energy efficient technologies. Consumption losses are reported as the percentage change between consumption in a baseline scenario BAU where transfers are postponed (as indicated in the legend) and consumption in the baseline scenario BAU where transfers start immediately in 2005. Consumption losses are cumulated from 2005 to 2100 and discounted at a rate of $3 \%$ p.a.

This is probably due to the following reasons: First, our model setup allows all regions to benefit from the global knowledge pool, in this case regarding energy-specific technological knowledge. Second, regions can benefit from technical progress in other regions through international transfers or in other words through commodity trade.

As expected, China suffers most from postponing international technology diffusion because it starts at a low energy productivity and is able to catch up fast, followed by the developing region INA. Europe suffers least due to its good initial energy productivity, followed by the USA and the Rest of the World. The gains from financing technology transfer appear to be higher in earlier periods since the process of growth and technological catching up is more pronounced in earlier periods than in later periods. Intuitively, early investments in technical progress are beneficial over the whole time horizon while late investments have a limited remaining scope.

Figure 2 plots the regional effects of climate policy POL as the difference between POL and BAU consumption relative to BAU consumption for each start date of financing. Consumption losses obviously slightly rise when postponing the financing of international technology diffusion. Basically, Figure 2 illustrates that our integrated assessment model generates consumption losses of less than one percent for all regions 


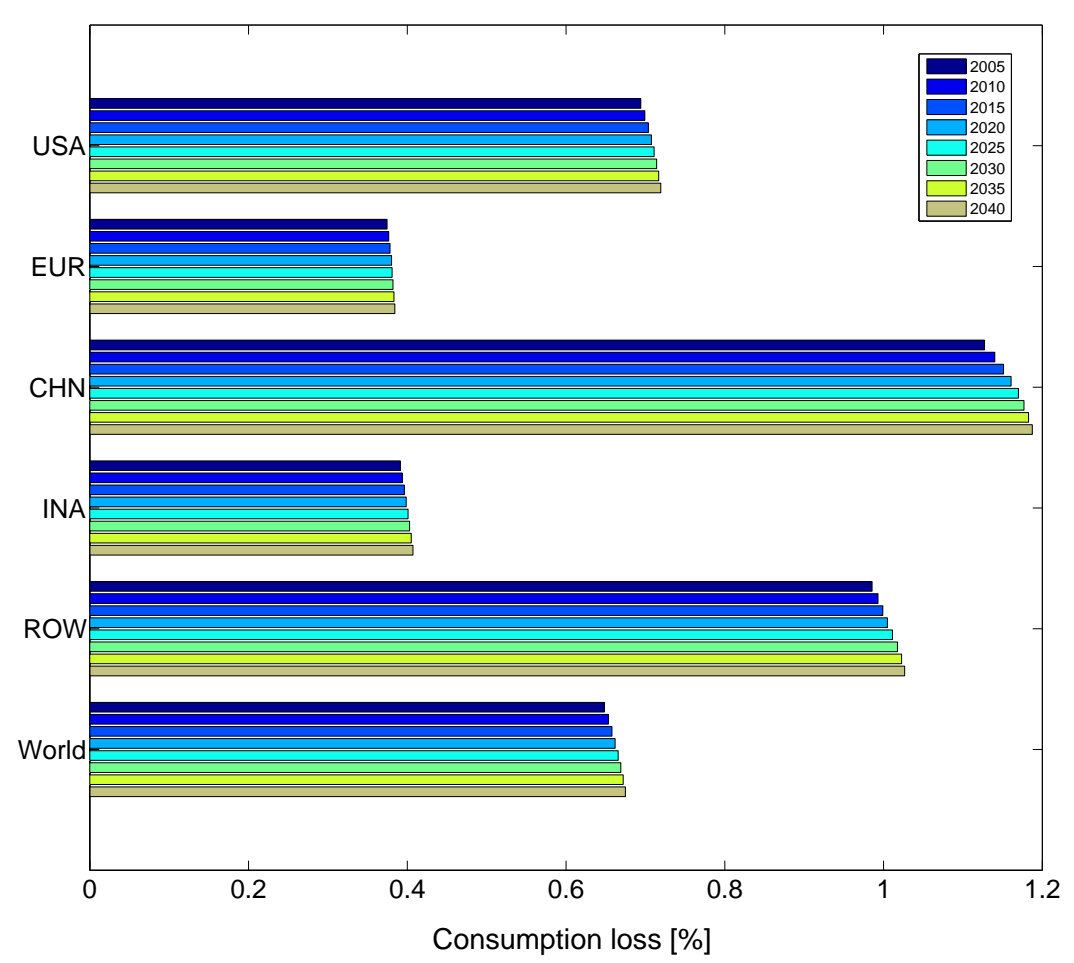

Figure 2: Regional effects of climate policy POL (carbon budget) for different start dates (as indicated in the legend) of international transfers of energy efficient technologies. Consumption losses are reported as the percentage change between POL and BAU consumption for each start date of transfers.

except China. China is accordingly affected most severely, followed by the region Rest of the World and the USA. Europe can probably benefit from its good energy productivity and the developing region INA from its low per-capita emissions in the context of interregional permit trading so that mitigation costs are low. However, most of the consumption gains from early technology transfer have already been exploited in BAU.

\section{Sensitivity}

This section first critically discusses model characteristics and then addresses them in a sensitivity analysis.

\subsection{Critical discussion}

Our integrated assessment model has the following characteristics: 
We represent endogenous innovation and imitation and thus international technology transfer in a stylized fashion. Our functional forms of modeling innovation and imitation follow the Schumpeterian model of endogenous growth. Other functional forms might lead to a different dynamic behavior, though. Also, from a micro-economic point of view, the implementation of the Schumpeterian model does not take profit maximization of firms and monopolistic power in intermediate production explicitly into account. In fact, our model reproduces the typical behavior of endogenous growth models on the macro level.

Moreover, in each region production is specified in form of a standard CES structure (as illustrated in Figure 4 in the Appendix) that assumes certain elasticities of substitution which determine the possibility of switching between energy, capital and labor and between specific energy inputs. This structure and the elasticity values influence mitigation costs.

In general, the calibration of any complex, dynamic, numerical model involves uncertainties. This is especially true with respect to modeling innovation and international technology diffusion and related expenditures. We build our calibration on econometric estimates. These estimates provide a range of appropriate parameter values but the estimated models do not match our model one by one. Furthermore, the comparison of model outcomes with reference data reveals a good match in most cases. Initial growth rates of energy productivity in Europe and the USA are slightly lower than in the reference data. In general, the sensitivity of the model with respect to policy induced effects appears small.

Basically, our model shows the typical behavior of North-South growth models, i.e. strong adjustment processes in early periods in terms of investment in capital and technology, and strong North-South transfers (from USA, EUR and ROW to INA and CHN; c.f. Lucas 1990). Consequently, most of the policy induced technology effects occur in early periods, too, while long-run growth paths evolve at low growth rates (c.f. Figure 6 in the Appendix) and are hardly affected by the policy experiments. On the contrary, under the assumption of distant future economic growth at a constant high rate, GDP and emissions and the resulting mitigation costs would be higher (c.f. Hübler 2011). Moreover, discounting gives a lower weight to future consumption and its policy induced changes and consequently influences mitigation costs as in every economic long-run analysis.

Furthermore, we only capture expenditures on the innovation and imitation of technologies that improve energy productivity on a macro-economic scale. We leave aside the direct international transfer of energy technologies like wind and solar power in 
this analysis. Taking this into account, would presumably strongly increase policy induced innovation and imitation and could further reduce mitigation costs. One would in particular expect a shift of innovation from fossil to non-fossil technologies. The REMIND model encompasses a full energy system module, though, which enables the early expansion of renewable energies and the decarbonization of energy supply in every region. Herein, the energy system module is calibrated to benchmark data. The future development of the energy mix represents only one exemplary scenario though.

Our policy analysis suggests relatively low mitigation costs of keeping a carbon budget of $400 \mathrm{Gt}$ for the time period 2005 to 2100 , given a baseline scenario of relatively low emissions.

Therefore, in summary all policy results need to be taken with some caution. They need to be interpreted with respect to the baseline scenario that we have calibrated based on econometric, historical and scenario data.

\subsection{Sensitivity analysis}

In the following, we address the aspects discussed above by carrying out a detailed sensitivity analysis for regional consumption losses stemming from climate policy POL based on the BAU scenario 'Default' that we have examined so far:

(1) We switch off the availability of all renewable energies and CCS (of coal, gas and biomass) in all regions ('-Renew'). (2) We change the constant elasticity of substitution in the upper CES level (c.f. Equation 7 and Figure 4 in the Appendix) to 0.2 and alternatively to 0.8 , while our standard value is 0.5 . (3) We vary the elasticity of technical progress with respect to related investments governed by the exponents $\sigma_{R}$ and $\sigma_{S}$ simultaneously by the same factors, namely two (twice the previous value) and 0.75. (4) We vary the strength of energy- and labor-specific innovation governed by $\lambda_{R}$ and (5) the strength of energy- and labor-specific imitation governed by $\lambda_{S}$ by the factors 1.5 and 0.75 . (6) Finally, we raise the strength of energy-specific innovation as well as imitation - keeping the strength of labor-specific technical progress unchanged - by the factor 1.5. We then reduce it to one third so that it has the same strength as for labor $\left(\lambda_{E}=\lambda_{L}\right)$. Herein, the range of the parameter value variations is limited by the capability of finding feasible and optimal solutions for the optimization problem as well as by economic reasoning.

The results are reported in Table 5 which shows consumption losses between POL and BAU, cumulated from 2005 until 2100 and discounted at a rate of $3 \%$ per year. ${ }^{14}$

\footnotetext{
${ }^{14}$ Energy-specific technology transfer is not delayed but allowed from 2005 on. Therefore, scenario
} 


\begin{tabular}{|c|c|c|c|c|c|c|}
\hline \multirow[b]{2}{*}{ Region } & \multirow[b]{2}{*}{ Default } & \multirow{2}{*}{$\begin{array}{c}(1) \\
\text {-Renew }\end{array}$} & \multicolumn{2}{|c|}{ (2) } & \multicolumn{2}{|c|}{ (3) } \\
\hline & & & $\sigma_{Y}=0.2$ & $\sigma_{Y}=0.8$ & $2 \cdot \sigma_{R / S}$ & $0.75 \cdot \sigma_{R / S}$ \\
\hline USA & 0.69 & 1.93 & 0.45 & 1.20 & 0.77 & 0.67 \\
\hline EUR & 0.37 & 1.32 & 0.28 & 0.52 & 0.40 & 0.36 \\
\hline $\mathrm{CHN}$ & 1.13 & 4.14 & 0.49 & 2.48 & 1.25 & 1.09 \\
\hline INA & 0.39 & 1.55 & 0.28 & 0.46 & 0.42 & 0.38 \\
\hline ROW & 0.99 & 0.29 & 0.30 & 2.11 & 1.08 & 0.95 \\
\hline \multirow[t]{2}{*}{ World } & 0.65 & 1.64 & 0.34 & 1.20 & 0.71 & 0.63 \\
\hline & \multicolumn{2}{|c|}{$(4)$} & \multicolumn{2}{|c|}{$(5)$} & \multicolumn{2}{|r|}{ (6) } \\
\hline Region & $1.5 \cdot \lambda_{R}$ & $0.75 \cdot \lambda_{R}$ & $1.5 \cdot \lambda_{S}$ & $0.75 \cdot \lambda_{S}$ & $1.5 \cdot \lambda_{E}$ & $0.33 \cdot \lambda_{E}$ \\
\hline USA & 0.65 & 0.71 & 0.63 & 0.72 & 0.48 & 1.20 \\
\hline EUR & 0.36 & 0.38 & 0.35 & 0.39 & 0.28 & 0.53 \\
\hline $\mathrm{CHN}$ & 1.07 & 1.15 & 1.05 & 1.15 & 0.76 & 2.05 \\
\hline INA & 0.39 & 0.39 & 0.44 & 0.32 & 0.27 & 0.68 \\
\hline ROW & 0.94 & 1.01 & 0.88 & 1.01 & 0.66 & 1.64 \\
\hline World & 0.62 & 0.66 & 0.62 & 0.65 & 0.45 & 1.10 \\
\hline
\end{tabular}

Table 5: Sensitivity analysis for regional mitigation costs reported as the percentage change between POL and BAU consumption. The losses are cumulated from 2005 to 2100 and discounted at a rate of $3 \%$ p.a.

The baseline scenario 'Default' is the same as in the previous analysis. Accordingly, global consumption losses exceed $0.5 \%$. The most striking increase in mitigation costs to more than $1.5 \%$ of global consumption occurs when switching of the availability of renewable energies and CCS in experiment (1) '-Renew'. Herein, China's consumption losses even rise to more than $4 \%$. Moreover, a significant increase in global consumption losses to more than $1 \%$ occurs when raising the elasticity of substitution in the upper CES nest in (2). Herein, the peak of global carbon emissions in BAU rises from below $16 \mathrm{Gt}$ in the standard scenario to almost 20Gt in experiment (2) where the elasticity of substitution is raised $\left(\sigma_{Y}=0.8\right)$. Obviously, the higher flexibility in the production structure already increases BAU production and emissions which overcompensates the resulting improved possibility to replace fossil fuel inputs in POL. The opposite applies to the scenario where the elasticity of substitution is reduced $\left(\sigma_{Y}=0.2\right)$.

On the contrary, the impact of the variation in most of the coefficients and exponents within our model of endogenous growth is surprisingly small. An exemption is the strength of energy-specific technical progress (based on innovation as well as imitation)

'Default' resembles the 2005 result in Figure 2. 
for a given strength of labor-specific technical progress as examined in experiment (6). Accordingly, setting the coefficient that governs the strength of energy-specific technical progress equivalent to the coefficient of labor-specific technical progress $\left(0.33 \cdot \lambda_{E}=\lambda_{L}\right)$ raises global losses to more than $1 \%$ and China's losses to about $2 \%$. On the contrary, mitigation costs are hardly affected in experiments (4) and (5) where the strength of energy and labor-specific innovation and imitation is varied simultaneously to the same extent. This result emphasizes the role of energy-specific technical progress relative to general or labor-specific technical progress with respect to mitigation costs.

\section{Conclusion}

We introduce endogenous directed technical change into integrated assessment based on theory and evidence. We distinguish innovation and imitation, in other words international technology transfer, and take the role of capital investment in creating and implementing new technologies into account. We study the regional pattern of mitigation costs in form of consumption losses induced by a global carbon budget-based climate policy.

Mitigation costs turn out to be robust with respect to a variation in the parameter values within our model of endogenous growth - except the coefficient of energy-specific relative to the coefficient of labor-specific innovation and imitation expenditures. This result suggests that a higher effectivity (in terms of technical progress per unit of investment) of energy-specific innovation and imitation expenditures can overcompensate rising emissions due to economic growth and thus reduce mitigation costs. However, the effectivity is exogenously determined by technological restrictions and at best partly susceptible by economic policy in the short-run in reality. In the medium- to long-run, the effectivity could be improved by emphasizing energy efficiency aspects in education, basic research, infrastructure, structural change and capacity building for $R \& D$ and for the absorption of foreign technologies. While our analysis exogenously adjusts a regional parameter representing education and absorptive capacity, further research may endogenize such a parameter in order to represent fundamental aspects of long-run development.

Motivated by the announcement of providing financial and technological transfers for developing countries at the Cancún 2010 summit, we examine interregional energysaving technology transfer starting at different points of time. Herein, in general, all regions gain from technology transfer due to its growth effect. China appears as the main beneficiary of early technology transfer, followed by the region of the developing coun- 
tries. These results suggest that enabling energy-saving technology transfer as soon as possible supports developing countries. The decarbonization of economic development, however, additionally requires the switch from fossil energies to renewable energies. In our model setup, such renewable energies are - to regionally different extents - available in all regions. Further research may therefore assess in how far the international transfer of renewable energies and the timing of such transfers can affect regional mitigation costs.

In general, our results suggest that endogenous energy-specific technical progress has already been strongly exploited in the business as usual (BAU) baseline due to its positive effect on consumption. This might be due to perfect foresight and regionally weighted global optimization in combination with energy scarcity. In reality, these baseline gains are not fully exploited on a market base due to risks and frictions and missing information (for possible baseline gains see McKinsey\&Company 2009). Realizing these gains may require active policy support in form of an integrated climate and energy policy concept. Due to these baseline gains, the early support of energy-saving technology transfer could be a 'carrot' to encourage developing countries to engage in climate protection.

\section{$7 \quad$ References}

Acemoglu, D., P. Aghion and F. Zilibotti (2003). Vertical Integration and Distance to Frontier. Journal of the European Economic Association 1(2-3), 630-638.

Acemoglu, D., P. Aghion and F. Zilibotti, (2006). Distance to Frontier, Selection, and Economic Growth. Journal of the European Economic Association 4(1), 37-74.

Acemoglu, D. (2002). Directed Technical Change. The Review of Economic Studies 69(4), 781-809.

Acemoglu, D. (2009). Introduction to Modern Economic Growth. Princeton University Press, New Jersey, USA.

Aghion, P. and P. Howitt (1992). A Model of Growth through Creative Destruction. Econometrica 60(2), 323-351.

Aghion, P. and P. Howitt (2009). The Economics of Growth. The MIT Press, Cambridge, Massachusetts, USA and London, England.

Allen, M.R., D.J. Frame, C. Huntingford, C.D. Jones, J.A. Lowe, M. Meinshausen and N. Meinshausen (2009). Warming caused by cumulative carbon emissions towards the trillionth tonne. Nature 458(7242), 1163.

Arrow, K. (1962). The Economic Implications of Learning by Doing. Review of 
Barreto, L. (2001). Technological Learning in Energy Optimisation Models and Deployment of Emerging Technologies. PhD Thesis ETH Zurich 14151, 277 pp., http://dx.doi.org/10.3929/ethz-a-004215893.

Bauer, N., O. Edenhofer S. and Kypreos (2006). Linking Energy System and Macroeconomic Growth Models. Journal of Computational Management Science (Special Issue on Managing Energy and the Environment) 5(1-2), 95-117.

Benhabib, J. and M. Spiegel (2005). Human capital and technology diffusion. In: P. Aghion and S. Durlauf (eds.), Handbook of Economic Growth, Elsevier, chapter 13.

Bosetti, V., C. Carraro, M. Galeotti, E. Massetti and M. Tavoni (2006). WITCH: A World Induced Technical Change Hybrid Model. The Energy Journal, Hybrid Modeling of Energy-Environment Policies: Reconciling Bottom-up and Top-Down, 13-38.

Bosetti, V., C. Carraro, E. Massetti and M. Tavoni (2008). International energy R\&D spillovers and the economics of greenhouse gas atmospheric stabilization. Energy Economics 30(6), 2912-2929.

Bosetti, V., C. Carraro, R. Duval and M. Tavoni (2011). What should we expect from innovation? A model-based assessment of the environmental and mitigation cost implications of climate-related R\&D. Energy Economics 33(6), 1313-1320.

Chichilnisky, G. and G. Heal (eds.) (2000). Environmental Markets - Equity and Efficiency. Columbia University Press, New York, USA.

Chichilnisky, G. and K.A. Sheeran (2009). Saving Kyoto: An Insider's Guide to How It Works, Why It Matters and What It Means for the Future. New Holland Publishers, London, Cape Town, Sydney, Auckland.

Crassous, R., J.-C. Hourcade and O. Sassi (2006). Endogenous Structural Change and Climate Change Targets - Modeling Experiments with Imaclim-R. The Energy Journal 27, Special Issue: Endogenous Technological Change and the Economics of Athmospheric Stabilisation, 259-276.

Crespo J., C. Martin and F. Velazquez, (2004). International technology spillovers from trade: the importance of the technological gap. Investigaciones Economicas, Fundacion SEPI 28(3), 515-533.

Diao, X., J. Rattsø and H.E. Stokke (2005). International spillovers, productivity growth and openness in Thailand: an intertemporal general equilibrium analysis. Journal of Development Economics 76, 429-450.

Edenhofer, O., N. Bauer and E. Kriegler (2005). The impact of technological change on climate protection and welfare: Insights from the model MIND. Ecological Economics 54, 277-292.

Edenhofer, O., C. Carraro, J.-C. Hourcade, K. Neuhoff, G. Luderer, C. Flachsland, M. Jakob, A. Popp, J. Steckel, J. Strohschein, N. Bauer, S. Brunner, M. Leimbach, H. Lotze-Campen, V. Bosetti, E. de Cian, M. Tavoni, O. Sassi, H. Waisman, R. Crassous-Doerfler, S. Monjon, S. Dröge, H. van Essen, P. del Rio, A. Türk (2009). RECIPE - The Economics of Decarbonization, Synthesis Report, 96 pp. 
Gerlagh, R. (2008). A climate-change policy induced shift from innovations in carbonenergy production to carbon-energy savings. Energy Economics 30, 425-448.

GCI (1990). Contraction and Convergence (C\&C) is the science-based, global climate policy framework proposed to the UN since 1990 by the Global Commons Institute. http://www.gci.org.uk/.

Goulder, L.H. and S.H. Schneider (1999). Induced Technological Change and the Attractiveness of $\mathrm{CO} 2$ Abatement Policies. Resource and Energy Economics 21, 211-253.

Greiner, A. and W. Semmler (2002). Externalities of investment, education and economic growth. Economic Modelling 19, 709-724.

Griffith, R., S. Redding and J. van Reenen (2003). R\&D and Absorptive Capacity: Theory and Empirical Evidence. Scandinavian Journal of Economics 105(1), 99-118.

Griffith, R., S. Redding and J. van Reenen (2004). Mapping the Two Faces of R\&D: Productivity Growth in a Panel of OECD Industries. The Review of Economics and Statistics 86(4), 883-895.

Griliches, Z. and F. Lichtenberg (1984). Interindustry Technology Flows and Productivity Growth: A Reexamination. Review of Economics and Statistics 66(2), 324-329.

Grossman, G. and E. Helpman (1991). Innovation and Growth in the Global Economy. The MIT Press, Cambridge, Massachusetts, USA and London, England.

Hübler, M. (2011). Technology Diffusion under Contraction and Convergence: A CGE Analysis of China. Energy Economics 33(1), 131-142.

IEA (2010). Data Services. International Energy Agency, Paris, France. http://data. iea.org/ieastore/default.asp.

IPCC (2000). Special Report on Emissions Scenarios (SRES). Intergovernmental Panel on Climate Change, Geneva, Switzerland.

http://www.grida.no/publications/other/ipcc_sr/?src=/climate/ipcc/ emission/.

Kahouli-Brahmi, S. (2008). Technological learning in energy-environment-economy modelling: A survey. Energy Policy 36, 138-162.

Kemfert, C. (2005). Induced technological change in a multi-regional, multi-sectoral, integrated assessment model (WIAGEM) Impact assessment of climate policy strategies. Ecological Economics 54, 293-305.

Kneller, M. (2005). Frontier technology, Absorptive Capacity and Distance, Oxford Bulletin of Economics and Statistics 67(1), 1-23.

Kossoy, A. and P. Ambrosi (2010). State and Trends of the Carbon Market 2010. Carbon Finance at the World Bank, Environment Department, Washington, DC, USA.

Leimbach, M. and Baumstark, L. (2010). The impact of capital trade and technological spillovers on climate policies. Ecological Economics 69, 2341-2355. 
Leimbach, M., N. Bauer, L. Baumstark and O. Edenhofer (2010a). Mitigation Costs in a Globalizing World: Climate Policy Analysis with REMIND-R. Environmental Modeling and Assessment 15, 155-173.

Leimbach, M., N. Bauer, L. Baumstark, M. Lüken and O. Edenhofer (2010b). Technological Change and International Trade: Insights from REMIND-R. The Energy Journal 31, Special Issue: The Economics of Low Stabilization, 109-136.

Löschel, A., and V.M. Otto (2009). Technological Uncertainty and Cost-Effectiveness of CO2 Emission Reduction. Energy Economics 31, 4-17.

Lucas, R. (1990). Why Doesn't Capital Flow from Rich to Poor Countries? The American Economic Review 80(2), 92-96.

Lüken, M., O. Edenhofer, B. Knopf, M. Leimbach, G. Luderer and N. Bauer (2011). The role of technological availability for the distributive impacts on climate change mitigation policy. Energy Policy 39, 6030-6039.

McKinsey\&Company (2009). Pathways to a Low-Carbon Economy. Version 2 of the Global Greenhouse Gas Abatement Cost Curve, 192 pp.

https://solutions.mckinsey.com/climatedesk/default.aspx.

Meinshausen, M., N. Meinshausen, W., Hare, S.C.B. Raper, K. Frieler, R. Knutti, D.J. Frame, M.R. Allen (2009). Greenhouse-gas emission targets for limiting global warming to $2^{\circ} \mathrm{C}$. Nature $458,1158-1163$.

Negishi, T. (1972). General Equilibrium Theory and International Trade. NorthHolland Publishing Company, Amsterdam.

Nelson, R. and E. Phelps (1966). Investment in Humans, Technological Diffusion, and Economic Growth. The American Economic Review, Papers and Proceedings 61, 69-75.

Nicita, L., C. Carraro and E. Massetti (2009). How Does Climate Policy Affect Technical Change? An Analysis of the Direction and Pace of Technical Progress in a Climate-Economy Model. The Energy Journal, Climate Change Policies after 2012, $7-38$.

Otto, V.M., Dellink, R. and A. Löschel (2007). Energy Biased Technical Change - A CGE Analysis. Resource and Energy Economics 29 (2), 137-158.

Otto, V.M., A. Löschel and J. Reilly (2008). Directed Technical Change and Differentiated Climate Policy. Energy Economics 30 (6), 2855-2878.

Popp, D. (2004). ENTICE: endogenous technological change in the DICE model of global warming. Journal of Environmental Economics and Management 48, 742-768.

Popp, D. (2006). Innovation in climate policy models: Implementing lessons from the economics of R\&D. Energy Economics 28, 596-609.

Romer, P. (1990). Endogenous Technological Change. Journal of Political Economy 98, $71-102$.

Schankerman, M. (1981), The Effects of Double-counting and Expensing on the 
Measured Returns to R\&D. Review of Economics and Statistics 63(3), 454-458.

Scherer, F. (1982). Inter-industry Technology Flows and Productivity Growth. Review of Economics and Statistics 64(4), 627-634.

Scherer, F. (1984). Using Linked Patent and R\&D Data to Measure Inter-industry Technology Flows. In: Z. Griliches (ed.), R\&D, Patents, and Productivity, NBER and University of Chicago Press, Chicago, USA.

SEI (2006). Science and Engineering Indicators. National Science Foundation, USA. http://www.nsf.gov/statistics/seind06/c4/c4s6.htm.

Tanaka, K. and E. Kriegler (2007). Aggregated Carbon Cycle, Atmospheric Chemistry, and Climate Model (ACC2). Reports on Earth System Science, 40. Max-PlanckInstitute of Meteorology, Hamburg, Germany.

UN (2008). World Population Prospects - The 2008 Revision. United Nations, New York, USA. http://www.un.org/esa/population/publications/wpp2008/wpp2008_ highlights.pdf .

WDI (2010). World Development Indicators. The World Bank, Washington DC, USA. http://data.worldbank.org/data-catalog/world-development-indicators.

World Bank (2010). Climate Investment Funds (CIF). The World Bank, Washington DC, USA. http : //www.climateinvestmentfunds.org/cif/node/2.

Zachariadis, M. (2003). R\&D, Innovation, and Technological Progress: A Test of the Schumpeterian Framework without Scale Effects. The Canadian Journal of Economics 36(3), 566-586. 


\section{Appendix}

\begin{tabular}{ll}
\hline Symbol & Explanation \\
\hline \hline$t=\{2005,2010, . .2100\}$ & Time (years in 5-year steps) \\
$r=\{I N A, C H N$, & Regions (INA: Africa, Latin America, \\
$R O W, E U R, U S A\}$ & India and other Asia - CHN: China - \\
& ROW: Middle East, Japan, Russia, rest of the world - \\
& EUR: Europe - USA: United States of America) \\
$i=\{L, E\}$ & Factors affected by technical progress (labor, energy) \\
$Y_{r t}$ & Production (income) \\
$M_{r t}$ & Net imports \\
$C_{r t}$ & Consumption \\
$A_{r i t}$ & Technology level \\
$\bar{A}_{i t}$ & Average global technology level (technology pool) \\
$K_{r t}$ & Capital input \\
$L_{r t}$ & Labor input \\
$E_{r t}$ & Energy input \\
$I_{r t}$ & Investment in capital \\
$Q_{r t}$ & Investment in the energy system \\
$R_{r i t}$ & Innovation or R\&D expenditures \\
$S_{r i t}$ & \\
\hline & \\
& \\
& \\
& \\
& \\
&
\end{tabular}

Table 6: Sets and endogenous variables. 


\begin{tabular}{llrrrrr}
\hline Symbol & Explanation & \multicolumn{4}{c}{ Value } \\
\hline \hline \multirow{2}{*}{$\lambda_{i}$} & Factor specialty of technical progress & L: & 1 & E: & 3 \\
$\lambda_{r 2005}$ & Education level in 2005 & INA: & 0.3 & CHN: & 0.7 \\
& & ROW: & 0.4 & EUR: & 0.75 \\
& & USA: & 0.9 & & \\
$\lambda_{R} / \lambda_{S}$ & Coefficient of innovation/imitation expd. & R: & 0.4 & S: & 0.12 \\
$\sigma_{R} / \sigma_{S}$ & Exponent of innovation/imitation expd. & R: & 0.1 & S: & 0.01 \\
$\sigma_{A} / \sigma_{I}$ & Exponent of tech. gap/investment & A: & 1 & I: & 1 \\
& & & & & \\
\hline
\end{tabular}

Table 7: Exogenous parameters. 


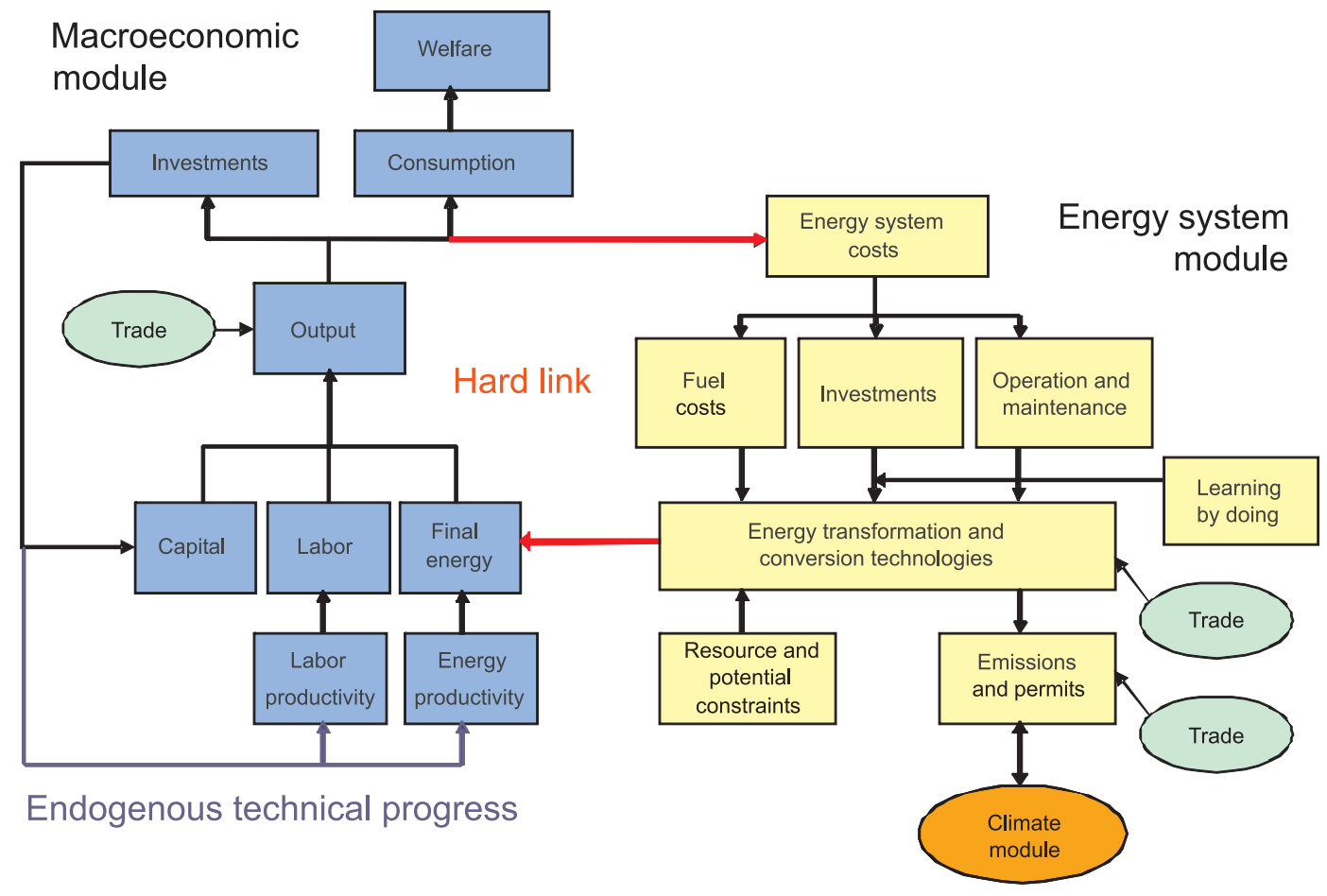

Figure 3: The REMIND modules and their interaction. 


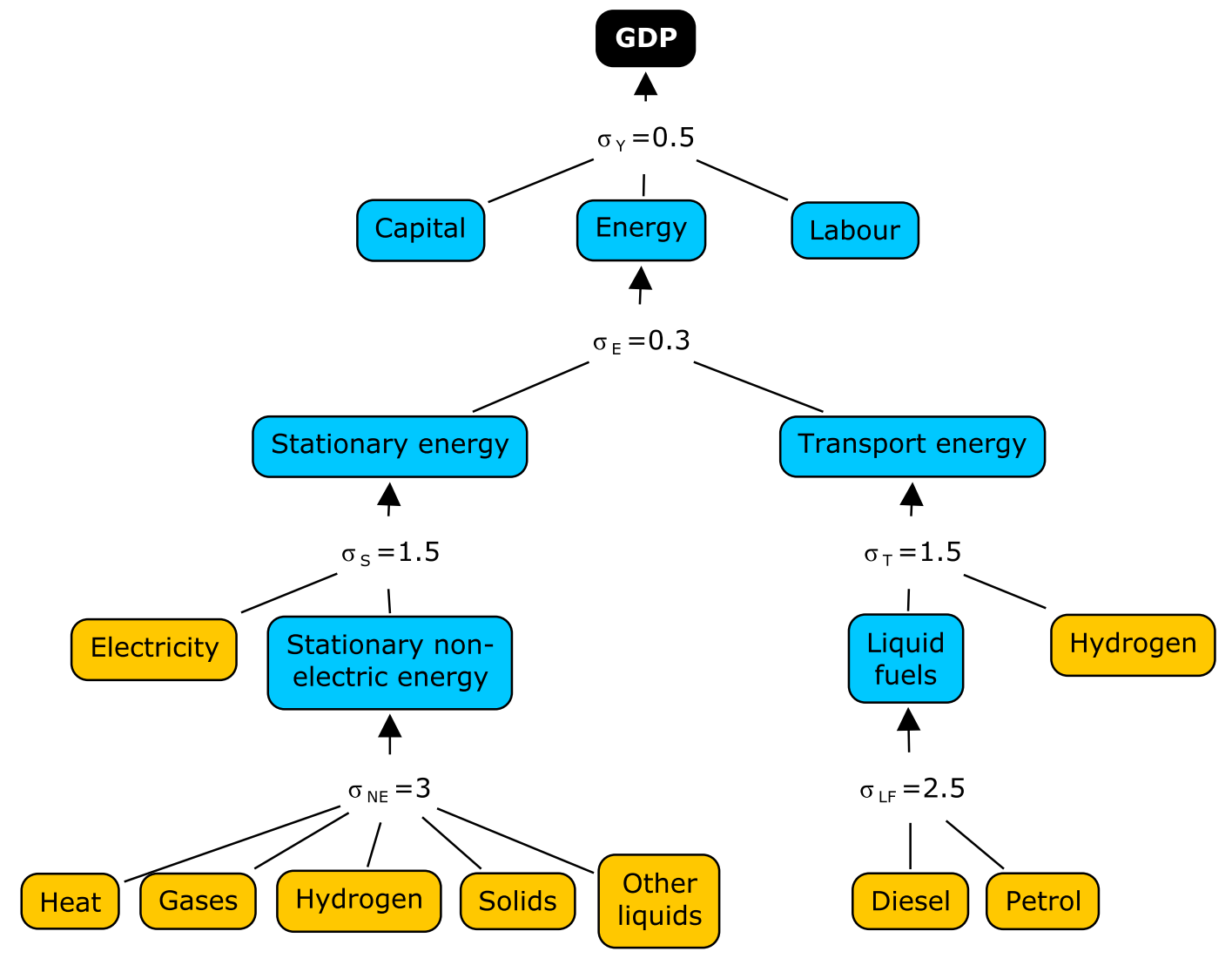

Figure 4: The CES structure of the regional REMIND production function; $\sigma$ indicates constant elasticities of substitution. 


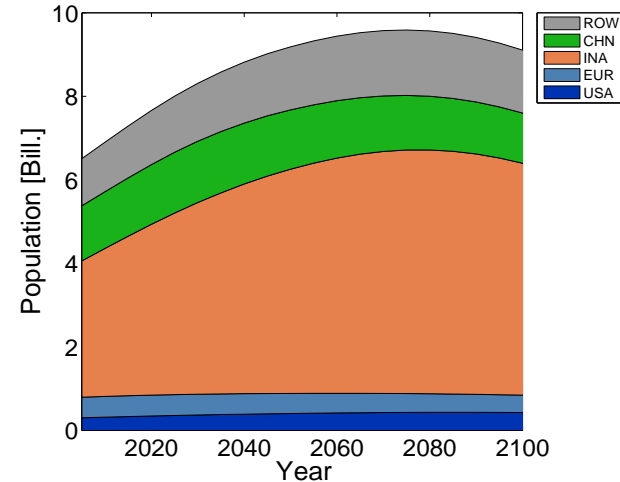

(a)

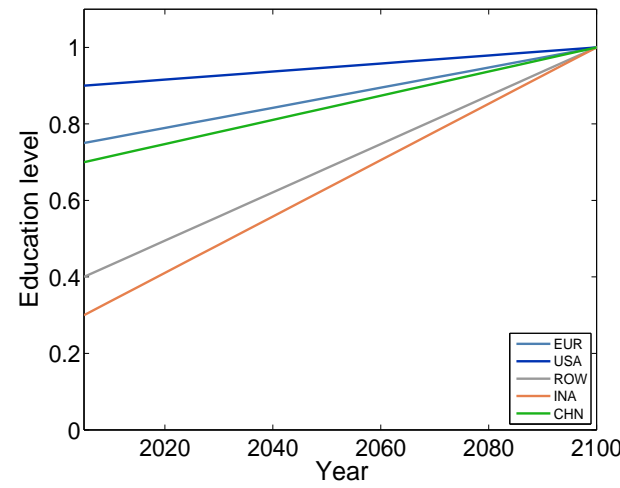

(c)

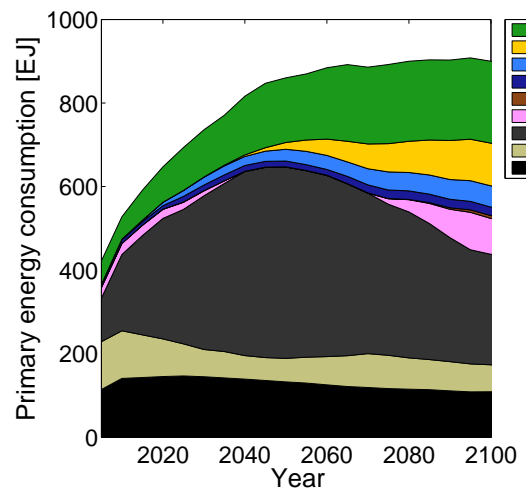

(e)

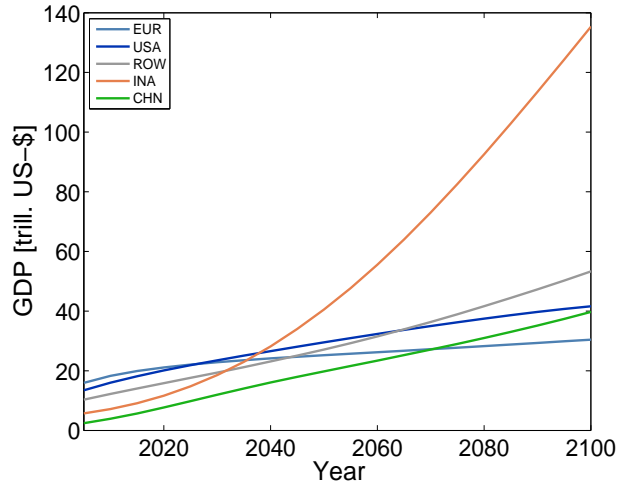

(b)

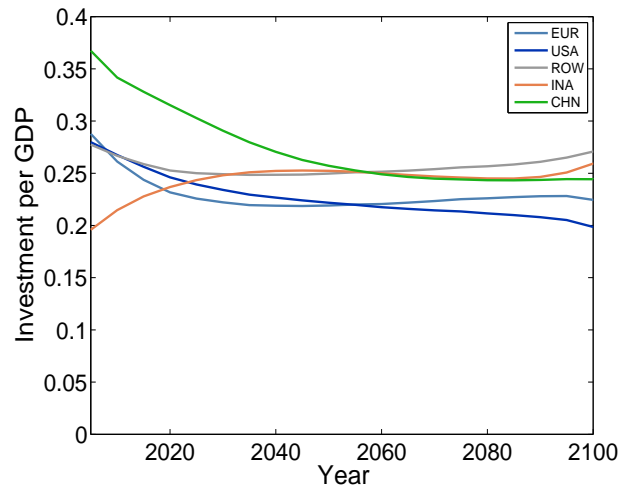

(d)

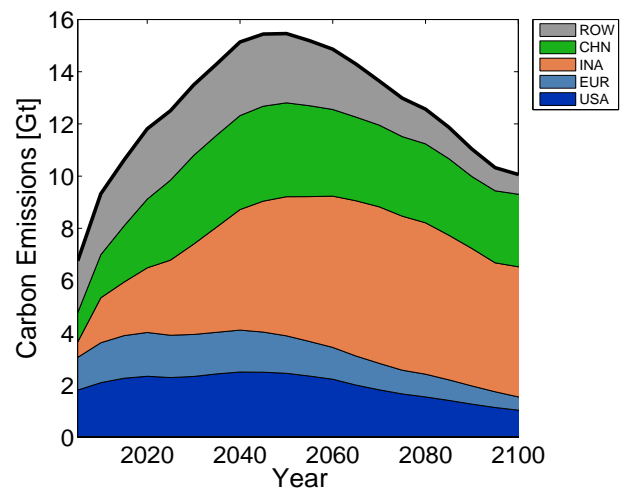

(f)

Figure 5: Simulation results for BAU. 


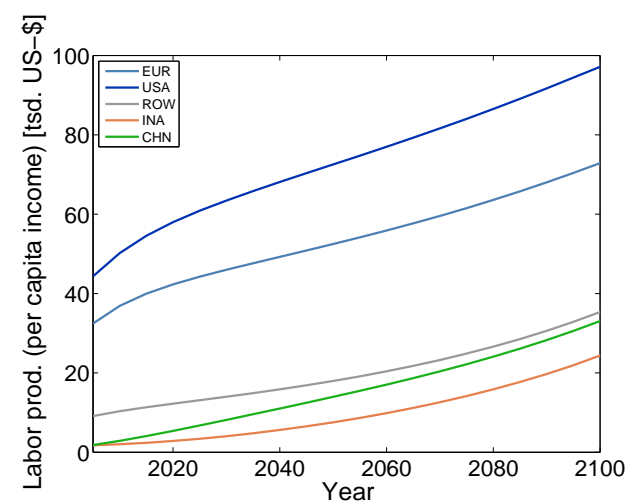

(a)

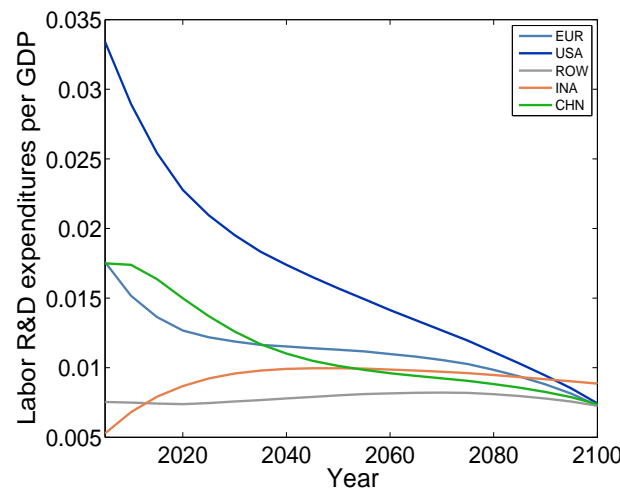

(c)

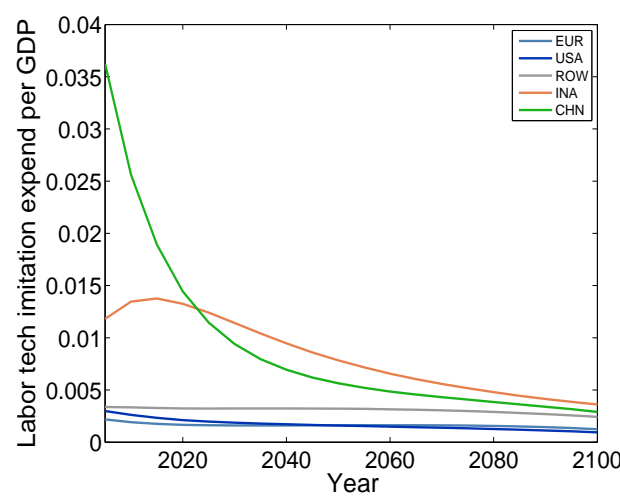

(e)

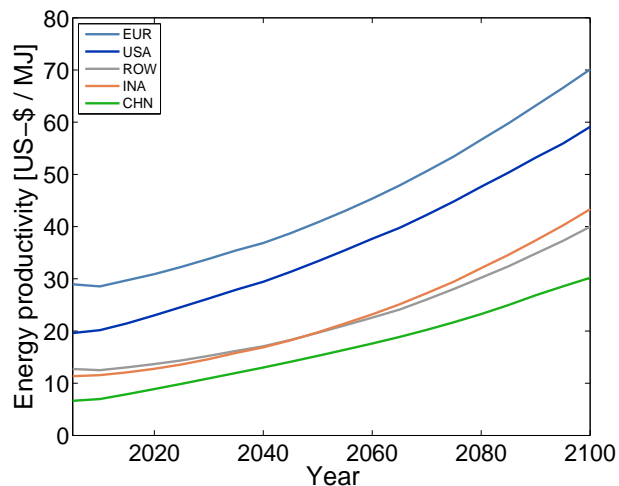

(b)

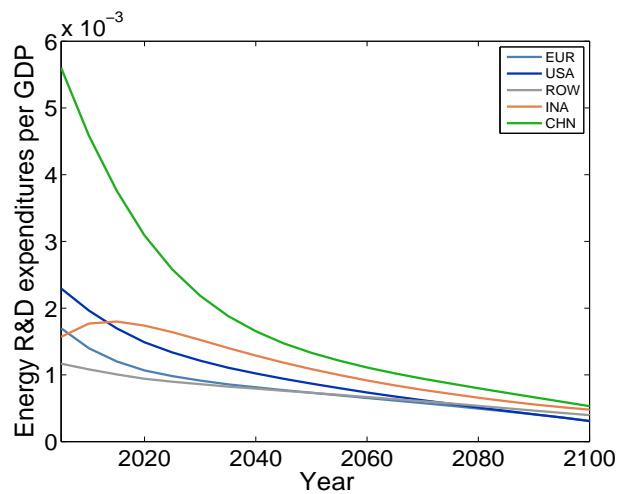

(d)

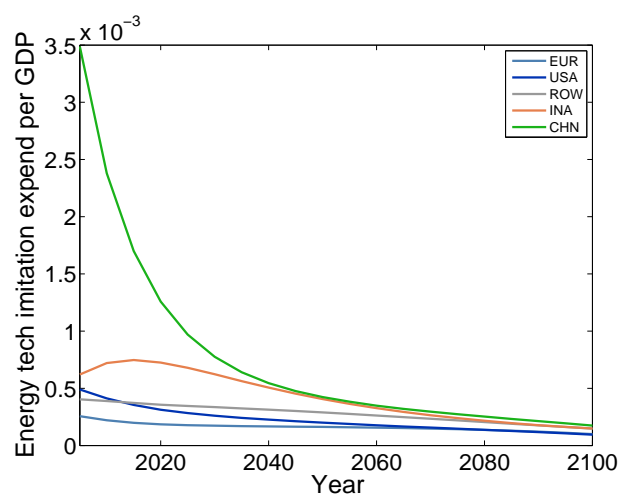

(f)

Figure 6: Simulation results for BAU. 


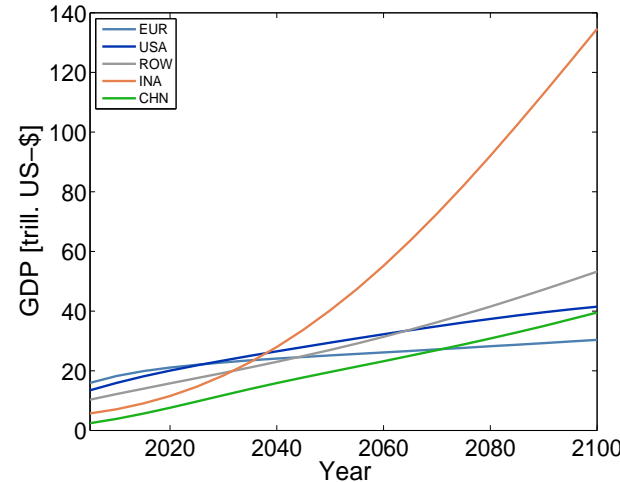

(a)

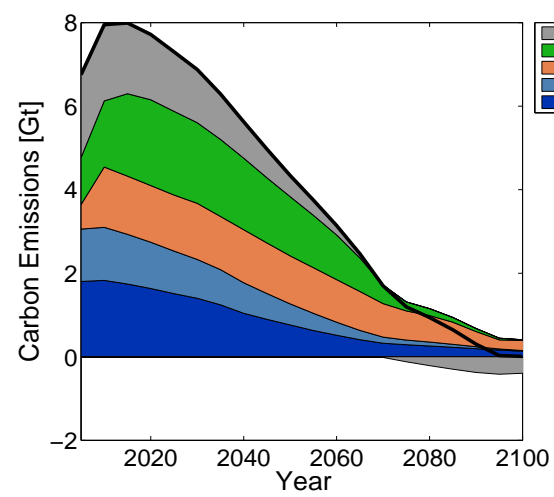

(c)

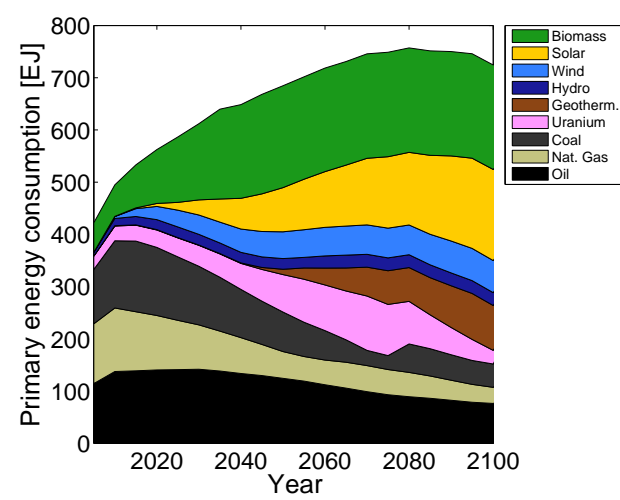

(e)

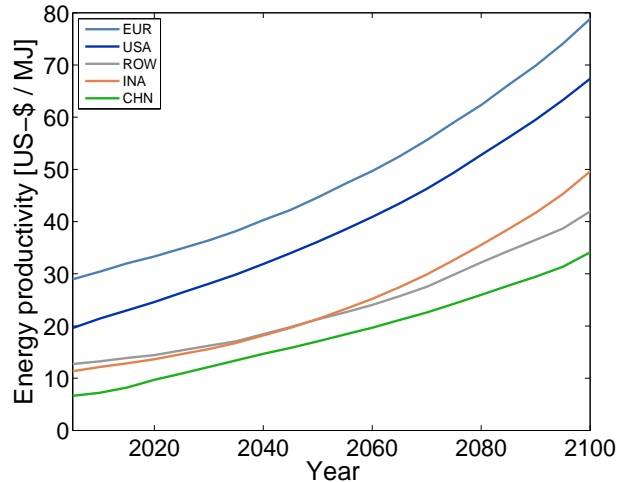

(b)

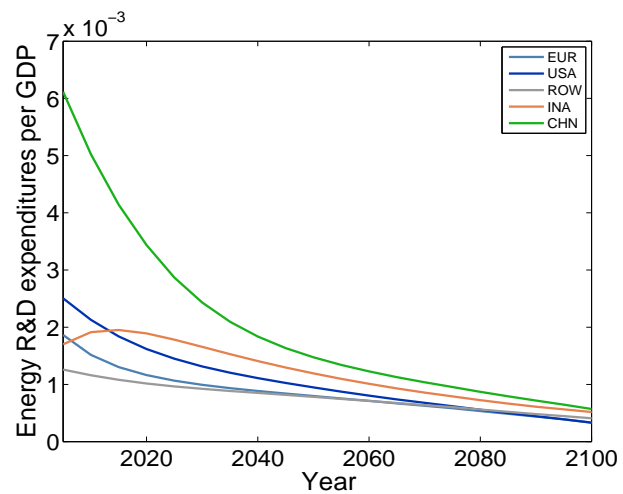

(d)

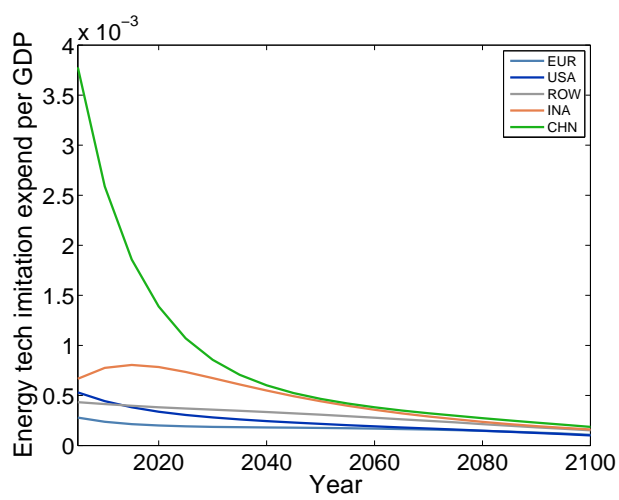

(f)

Figure 7: Simulation results for POL. 